\title{
TERRITORIO, FISCALIDAD Y ACTIVIDAD MILITAR EN LA FORMACIÓN DE UN ESPACIO FRONTERIZO. LA CONSOLIDACIÓN DE TORTOSA COMO LÍMITE EXTREMO DEL AL-ANDALUS OMEYA*
}

\author{
TERRITORY, TAX POLICIES AND MILITARY ACTIVITY DURING \\ THE FORMATION OF A FRONTIER SPACE. THE CONSOLIDATION OF \\ TORTOSA AS THE FURTHERMOST FRONTIER OF UMAYYAD AL-ANDALUS
}

\author{
JOAN NEGRE \\ Universitat Autònoma de Barcelona \\ https://orcid.org/0000-0002-2804-1467 \\ JOSEP SUÑÉ \\ Universitat de Barcelona \\ https://orcid.org/0000-0002-5741-4402
}

\begin{abstract}
Resumen: El objetivo principal de este trabajo es el de analizar los cambios en el control territorial andalusí de la circunscripción de Tortosa durante el período omeya mediante el estudio de tres ejes principales: la organización administrativa de sus dominios; la implementación de una fiscalidad eficiente con sus correspondientes mecanismos recaudatorios; $y$, finalmente, la actividad militar en la frontera a través de la construcción de fortificaciones y los contingentes allí movilizados. Para ello, se ha realizado un análisis crítico de las fuentes escritas y arqueológicas de las que se dispone para este territorio.
\end{abstract}

Palabras clave: al-Andalus; territorio, fiscalidad; ejército; emirato; califato; fortificaciones.

Abstract: This work focuses on analysing the changes in the territorial control of Tortosa during the Umayyad period through three main lines of approach: the administrative organisation of its domains, the implementation of efficient tax policies and tribute collection mechanisms, and military activity regarding fortress construction and troop mobilisation. In this way, this text presents a critical analysis of written and archaeological sources in order to undertake a historical interpretation of the process under study within this territory.

Keywords: al-Andalus; territory; tax policies; military; emirate; caliphate; fortresses.

\section{SUMARIO}

1. Introducción.- 2. La organización administrativa de Tortosa durante el emirato.2.1. ¿Continuidad o ruptura? Circunscripciones urbanas y distritos territoriales.- 2.2. La descentralización de la frontera reflejada en su actividad militar.- 3. Hacia un nuevo modelo de estado: las reformas de 'Abd al-Raḥmān al-Nāṣir.-3.1. Entre la organización

\footnotetext{
* Trabajo realizado dentro del Grupo de Investigación Consolidado OCORDE (2017SGR805), en el marco del proyecto "Génesis de la nobleza medieval: fortificaciones y poderes territoriales en el nordeste peninsular durante los siglos VIII-XI” (HAR2015-63661-P; MINECO-FEDER).

Los autores queremos agradecer los comentarios y críticas que el Dr. Jesús Lorenzo ha realizado a nuestro texto, permitiéndonos mejorar algunos aspectos del mismo. También queremos agradecer las observaciones realizadas por los dos revisores anónimos del documento, que han contribuido a la mejora del manuscrito definitivo.
}

Citation / Cómo citar este artículo: Negre, Joan; Suñé, Josep (2019), Territorio, fiscalidad y actividad militar en la formación de un espacio fronterizo. La consolidación de Tortosa, como límite extremo de Al-Andalus Omeya, "Anuario de Estudios Medievales" 49/2,pp. 705-740. https://doi.org/10.3989/aem.2019.49.2.12

Copyright: (C) 2019 CSIC. Este es un artículo de acceso abierto distribuido bajo los términos de la licencia de uso y distribución Creative Commons Reconocimiento 4.0 Internacional (CC BY 4.0). 
fiscal y la defensa de Dār al-Islām.- 3.2. El papel de los husụūn en la articulación de los aqālìm. 3.3. El proceso de estatización de la frontera a través de sus contingentes militares.- 4. Conclusiones.- Bibliografía citada.

\section{INTRODUCCIÓN}

En el pasado, diversos estudios han tratado el estudio del control territorial en al-Andalus, aunque siempre ha primado la visión global sobre el conjunto del territorio o, de forma más acotada, sobre la frontera superior ${ }^{1}$. Es por ello que el extremo oriental de este límite con los territorios cristianos siempre ha sido tratado de forma tangencial. A pesar de ello, diversos aspectos vinculados al análisis histórico del pasado andalusí del territorio de Tortosa han sido abordados de forma sistemática en dos tesis doctorales recientes, a partir de las cuales se ha desarrollado ahora un estudio más extenso y exhaustivo de esta cuestión ${ }^{2}$. Este trabajo pretende, por tanto, mostrar los cambios que se produjeron a lo largo de los primeros tres siglos de vida de al-Andalus en relación a la ordenación y la defensa territorial del límite más alejado de sus dominios. Con este propósito, pondremos el foco de atención en tres elementos clave para entender este proceso: la organización administrativa del territorio, la implantación de un sistema fiscal eficiente y la actuación del ejército en cuanto a su movilización y a la fortificación de la frontera. Para ello nos valdremos de todas las fuentes documentales y arqueológicas existentes hasta la fecha, interrelacionadas en el análisis crítico del proceso histórico bajo estudio ${ }^{3}$.

\section{LA ORGANIZACIÓN ADMINISTRATIVA DE TORTOSA DURANTE EL EMIRATO}

No existe documento árabe alguno que describa con precisión los límites de Tortosa y la división administrativa que se aplicó en su circunscripción territorial. Se trata de un problema que parece generalizarse a lo largo de los territorios del Islam hasta mediados del siglo IX ${ }^{4}$.

En el caso específico de la península Ibérica hay un cierto consenso entorno a la progresiva implantación de un sistema provincial original desde

\footnotetext{
${ }^{1}$ Mu'nis 1957; Molina, Ávila 1985; Vallvé 1986; Manzano 1991; Souto 1992; Sénac 2000; Meouak 2000; Valor, Ramírez 2001.

${ }^{2}$ Negre 2013a; Suñé 2017.

${ }^{3}$ El sistema de transliteración del árabe utilizado responde a las siguientes grafías para el alifato: $\bar{a}, \mathrm{~b}, \mathrm{t}, \underline{\mathrm{t}}, \breve{\mathrm{g}}, \mathrm{h}, \mathrm{h}, \mathrm{d}, \underline{\mathrm{d}}, \mathrm{r}, \mathrm{z}, \mathrm{s}, \breve{s}, \mathrm{~s}, \mathrm{~d}, \mathrm{t}, \mathrm{z},{ }^{\prime}, \dot{\mathrm{g}}, \mathrm{f}, \mathrm{q}, \mathrm{k}, 1, \mathrm{~m}, \mathrm{n}, \mathrm{h}, \mathrm{w} / \overline{\mathrm{u}}, \mathrm{y} / \overline{\mathbf{1}}$.

${ }^{4}$ Mu'nis 1957, p. 79; Miquel 2001,pp. 100-101; Lorenzo en prensa.
} 
pocas décadas después de la conquista ${ }^{5}$. Aun así, siguen evaluándose otras propuestas, no excluyentes con lo anterior, que defienden la pervivencia, al menos durante los momentos iniciales de al-Andalus, de algunas estructuras de administración visigodas ${ }^{6}$. Entre otros factores, estos planteamientos toman en consideración el aparente interés mostrado hacia las formas de división territorial antiguas por la primera recopilación geográfica hecha por un andalusí. Así, Aḥmad b. Muhammad al-Rāzī recogía en sus textos la organización diocleciana en seis provincias ${ }^{7}$ o la separación de la península en dos grandes regiones: la de levante, antigua Citerior, y la de poniente, Ulterior ${ }^{8}$. En este caso, sin embargo, se trata de un ejercicio de geografía histórica y no de la constatación de la pervivencia de estructuras administrativas anteriores ${ }^{9}$. Es más, la lista de provincias recogida por el cronista y geógrafo cortesano no se corresponde realmente con la división diocleciana, sino con una relación de sedes episcopales del siglo VII ${ }^{10}$, lo que apunta hacia un interés particular por las ciudades y sus circunscripciones.

\section{1. ¿Continuidad o ruptura? Circunscripciones urbanas y distritos territoriales}

En cuanto a la ordenación territorial tras la conquista, el primer elemento que destaca en los escritos son las circunscripciones urbanas, denominadas genéricamente por las fuentes árabes como a $m \bar{a} l^{l l}$ (sing. 'amal) y constituidas por un centro territorial y su jurisdicción (wilāya). Diversos estudios, desde ópticas complementarias, han propuesto ya el papel protagonista que estos dominios urbanos jugarían en esta primera implantación del Estado andalusí1 ${ }^{12}$. Es necesario destacar, sin embargo, que el análisis de los

\footnotetext{
${ }^{5}$ Meouak 2000,pp. 106-108; Manzano 2006, p. 425.

${ }^{6}$ Mu'nis 1957, pp. 79-81; Acién 2000, pp. 430-432.

${ }^{7}$ AMA, pp. 198-201; el autor atribuye la división provincial diocleciana al emperador Constantino. La crónica de al-Rāzī se conoce hoy en día a través de citas indirectas en otros autores árabes y por la Crónica del Moro Rasis, una edición crítica de tres copias de la traducción al castellano (finales s. XV), de la traducción al portugués (s. XIV), de la traducción al castellano, del original árabe (s. X). Los fragmentos que conocemos, por tanto, pueden ayudar a conocer y analizar el contenido general de la obra original, pero es necesario proceder con cautela en cuanto a datos que requieren de precisión.

${ }^{8}$ Ibidem, pp. 16-18.

${ }^{9}$ Manzano 2006, p. 424.

${ }^{10} \mathrm{CGpI}$, pp. 49-63.

${ }^{11}$ MII/1, ed. Makkī, p. 121; MII/2, p. 332; MIII, ed. Martínez Antuña, pp. 87, 118; MV, pp. 40,76 .

${ }^{12}$ Chalmeta 1991, p. 16; Souto 1992, p. 114; Acién, Manzano 2009, p. 336
} 
últimos concilios visigodos permite constatar cómo muchos de estos a $m \bar{a} \bar{l}$ eran a su vez coincidentes con las diócesis de distintas sedes episcopales visigodas, unas circunscripciones que durante el siglo VII se habrían convertido en importantes demarcaciones fiscales ${ }^{13}$. La administración de estas gobernaciones en las primeras décadas tras la conquista, siguiendo el planteamiento de la hipótesis continuista, se basaría en la dualidad entre un poder coactivo, ejercido por un 'ámil, y otro censitario, en manos del obispo de la sede $^{14}$. Sin embargo, esta división de atribuciones, que no parece haber sido homogénea a lo largo de la península, fue diluyéndose progresivamente allá donde se aplicó hasta quedar concentradas en la figura del gobernador todas las atribuciones del poder.

En el caso de Tortosa, no tenemos evidencias de la presencia de una doble titularidad, sin poder asegurar si esto se debe a la inexistencia de este mecanismo o a la poca información histórica que nos ha llegado sobre las primeras décadas de al-Andalus en la ciudad. El último obispo del que tenemos constancia en las fuentes escritas, Involato, parece jugar un papel importante en las relaciones de poder del Estado toledano entorno al año 696, pero no vuelve a aparecer con posterioridad. ${ }^{15}$ Los textos árabes que consignan las noticias más antiguas sobre la ciudad, ya en referencia al siglo IX, apuntan hacia la centralización del poder en manos de un único personaje, identificándose su territorio como un ' $a m a l^{16}$, cuya administración quedaba bajo el mando de un 'a $m i l^{17}$. También las fuentes latinas apuntan en esta dirección, pues durante la segunda de las tres campañas carolingias contra esta ciudad, en el año 808, se menciona al gobernador de Tortosa, 'Ubaydūn b. al-Ġamr, como $d u x^{18}$, un título de similares atribuciones en la sociedad franca.

En cuanto a los límites de su circunscripción, debieron ser variables a lo largo del tiempo, algo habitual en este período. Si bien durante el siglo VIII su límite septentrional vendría marcado por los confines con el territorio

\footnotetext{
${ }^{13}$ CGpI, pp. 49-63; Las atribuciones de los obispos en sus demarcaciones crecieron de forma significativa durante el siglo VI, llegando a su zenit con las disposiciones regias contempladas en el III Concilio de Toledo, del año 589, tal y como se desprende de la epístola De fisco Barcinonensi, de ese mismo año (Souviron 2009). En ella se confirma la supervisión episcopal sobre los agentes de los numerarios encargados de la recaudación fiscal, ejerciendo estas atribuciones en sus diócesis, que devienen, por tanto, las unidades de tributación más habituales.

${ }^{14}$ Acién 2000, p. 430; Acién, Manzano 2009, p. 336.

${ }^{15}$ DHV, p. 255.

${ }^{16} \mathrm{MII} / 2$, p. 6.

${ }^{17}$ MII/1, ed. Makkī, pp. 131, 405; MII/2, p. 3; MIII, ed. Martínez Antuña, pp. 106, 109; BML, II, p. 74.

${ }^{18}$ VHI, p. 326.
} 
de Barcelona, tras las campañas carolingias contra Tortosa a inicios del siglo IX, la influencia de Tortosa debió llegar hasta el río Llobregat $(\text { Runliqa } \bar{a} t \bar{u})^{19}$. En cuanto a su límite meridional, no hay indicios que apunten a que sobrepasara el ámbito del Desert de les Palmes (Castelló), quedando Burriana y Sagunt bajo la órbita de Valencia ${ }^{20}$. Se trata, pues, de un marco de actuación que tiende a ser coincidente -a grandes rasgos- con el de la antigua diócesis visigoda de Tortosa, que conocemos a partir del documento de consagración de su catedral tras la conquista cristiana de la ciudad, en el cual se la dota secundum antiquos limites ${ }^{21}$.

En una segunda escala de análisis, algunas de las fuentes árabes más cercanas al período emiral identifican subdivisiones territoriales aún menores al 'amal. Se trata de los ahwwāz (sing. hawz), término con el cual Ibn Hayyān define, por ejemplo, a los distritos de Tortosa que el emir alNāṣir recuperó durante su gran aceifa contra Pamplona en 924 ${ }^{22}$. Este mismo vocablo es utilizado de nuevo por el cronista cordobés para describir los distritos de otros a 'māl, en todos los casos alejados de la capital de la circunscripción: en Zaragoza incluye el de Tarazona y Borja ${ }^{23}$ y el de la fortaleza de Alcañiz ${ }^{24}$; en Valencia, el de la ciudad de al- 'Askar, a día de hoy identificada con el yacimiento del Tossal de la Morera, en Elx ${ }^{25}$ y, más lejos, en Algeciras, el de Gaucín ${ }^{26}$. Con este mismo significado, algunas pocas menciones en estas mismas fuentes utilizan también el término iqlìm, aunque en contextos alejados de la frontera, principalmente cerca de la capital cordobesa ${ }^{27}$.

Sin muchas más informaciones a las que acudir, creemos que estos distritos pueden definirse como pequeñas demarcaciones administrativas basadas en comarcas geográficas bien acotadas (valles, hoyas, sierras, etc.) en que se subdividirían los a $m \bar{a} l$. Con una acepción etimológica cercana al concepto de "derecho de propiedad" y vinculada por algunos arabistas a

\footnotetext{
${ }^{19}$ NT, vol. I, p. 128.

${ }^{20}$ AMA, pp. 37-38; UM, pp. 159-160; TA, pp. 19-20; Barceló 2009.

${ }^{21}$ DCT, doc. 301.

${ }^{22} \mathrm{MV}$, pp. 122, 127.

${ }^{23} \mathrm{MII} / 2$, p. 4.

${ }^{24} \mathrm{MV}, \mathrm{p} .123$.

${ }^{25}$ Ibidem, p. 122; Guichard 2007. En el estado actual de conocimientos sobre este asentamiento, puede plantearse también la posibilidad que las menciones a al- 'Askar en Al-Ya 'qūbī y Al- 'Uḍ̂̄ī, que lo sitúan en el territorio de Tudmīr, y las de Ibn Hayyān, que lo ubican en Valencia, no sean coincidentes.

${ }^{26} \mathrm{MV}$, p. 57.

${ }^{27}$ MII/1, ed. Makkī, p. 458.
} 
la acepción de "territorio" 28 , tal vez podría existir una cierta correspondencia entre los $a h w \bar{a} z$ emirales y los territoria visigodos. Estos últimos, bien presentes en el Liber iudicum y descritos como unidades fiscales de entidad inferior a la provincia o la civitas $^{29}$, tendrían a su cabeza un centro de orden inferior a la sede episcopal ${ }^{30}$. Son, por tanto, subdivisiones administrativas cuyos criterios de delimitación conocemos a través de las prácticas gromáticas contenidas en el Corpus Agrimensorum Romanorum, donde se indica que su perímetro se establecería a partir de la divisoria de aguas ( $d i$ vortium aquarum) que circunscribía una cierta cuenca de drenaje, así como con el recurso de otras referencias artificiales como caminos, monumentos o encrucijadas ${ }^{31}$.

De forma expeditiva, podemos aventurar que entre los $a h w \bar{a} z$ de Tortosa recuperados por al-Nāșir en 924 debieron contarse al menos una

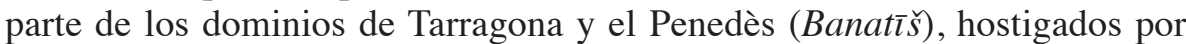
los condes de Barcelona desde finales del siglo IX ${ }^{32}$. Respecto al primero de estos posibles distritos, parece haber contado con una cierta actividad, principalmente portuaria, durante el primer siglo de implantación andalusí en la península Ibérica ${ }^{33}$. Esto contrasta, sin embargo, con el hecho de que no conozcamos el nombramiento de ningún gobernador para esta ciudad. Si tomamos como referencia las listas de designaciones para Tortosa y Barcelona en el mismo período podemos aventurar que, a mediados del siglo VIII, Tarragona ya habría perdido su estatus capitalino. El caso de esta ciudad resulta paradigmático como ejemplo del abandono progresivo de los límites administrativos anteriores en favor de aquellos vinculados a las ciudades elegidas por los conquistadores. Aun así, este territorio conservaría una cierta estructura de poblamiento y algunos sitios fortificados, si atendemos a la noticia de la destrucción de loca, castella y municipia en el camino entre Tarragona y Tortosa durante la expedición de Ludovico Pío en 804 o 806 o a las evidencias arqueológicas ${ }^{34}$.

\footnotetext{
${ }^{28}$ Meouak 2000,p. 107.

${ }^{29}$ Probablemente también de la diócesis a partir del s. VII, momento en el cual, como hemos indicado anteriormente, estas demarcaciones devendrán unidades territoriales principales del ejercicio fiscal.

${ }^{30}$ Martí 1995,p. 44.

${ }^{31}$ CAR, pp. 64-65, 74; Andreu 2012. Una propuesta metodológica para su restitución en Negre 2013a, pp. 288-292.

${ }^{32}$ TA, p. 66; MV, p. 65; BML, II, p. 172.

${ }^{33}$ Adserias, Pociña, Remolà 2000; Rodríguez, Macías 2016, 2018.

${ }^{34}$ VHI, p. 332; Gonzalo 2013, 2015.
} 


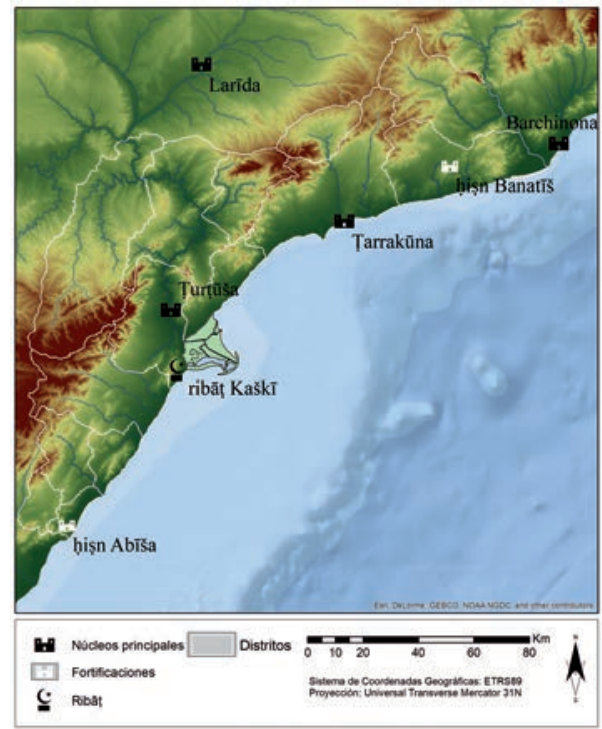

Fig. 1. Principales enclaves mencionados en el texto y posibles distritos (territoria-aḥwāz) definidos a partir de la delimitación e interpretación crítica de las cuencas de drenaje y sus divisorias de aguas.

En cuanto al segundo de estos distritos, la arqueología aporta información destacable para precisar el alcance de esta demarcación. La fortaleza de Olèrdola, mencionada como hișn Banatī̌s por al-Idrīs $\bar{s}^{35}$, cuenta con testimonios materiales que apuntan a su ocupación durante gran parte del siglo IX $^{36}$, momento en el cual está fuera de toda duda que este espacio pertenecía al ámbito de control de al-Andalus. Este enclave controlaba una pequeña demarcación, documentada en las fuentes árabes como faḥs Banatī̌̌ o como territorio Penetese en las latinas ya desde el año $917^{37}$. Conjuntamente con esta fortificación habrían funcionado otros elementos defensivos, principalmente torres, como las de Castellvell de la Marca y de Rosanes, actualmente bajo estudio $^{38}$. El Penedès, por tanto, conformaría la frontera más extrema de al-Andalus durante el siglo IX, tras la caída de Barcelona, y resistió los envites cristianos hasta el primer tercio de la siguiente centuria, momento a partir del cual empieza la expansión condal en este territorio ${ }^{39}$.

\footnotetext{
${ }^{35} \mathrm{UM}, \mathrm{pp} .162-163$.

${ }^{36}$ Molist, Bosch 2012; Martí 2017, p. 683.

${ }^{37} \mathrm{CSCV}$, doc. 9.

${ }^{38}$ Martí 2017, pp. 684-685; Folch, Gibert, Gonzalo, Martí, Martínez 2018.

${ }^{39}$ Gibert 2011, pp. 113, 259, 420, 433, 441.
} 
Ya sin constatación en las fuentes árabes, en el límite meridional de Tortosa encontramos aún otro territorium tardoantiguo identificable y con ocupación constatable durante el período emiral. Se trata de Lubricatum, cuyo étimo haría referencia al entorno general del Prat de Cabanes, zona de marismas y terrenos cenagosos, y que habría dado nombre a una mansio situada dentro de sus límites y recogida por los itinerarios altomedievales de la Via Augusta ${ }^{40}$. Arqueológicamente, hemos identificado la posta con el yacimiento de El Tancat (Cabanes), excavado hace pocos años y que presenta una ocupación continuada hasta el siglo VIII ${ }^{41}$. Este mismo topónimo aparece documentado por al-Idrīsīe, quien identifica una fortaleza de Luriqāt, y por Ibn al-Abbār, que menciona el sitio de Lubriqa $t^{42}$. Parece claro, por tanto, que nos encontramos ante un territorio que debió contar con un poblamiento estable durante el período omeya, detectado en prospección ${ }^{43}$ y confirmado por la construcción del ḥiṣn de $A b \bar{\imath} \breve{s} a$ a inicios del siglo X, como centro territorial de este distrito ${ }^{44}$.

Esta primera estructuración territorial, basada en circunscripciones urbanas amplias y pequeños distritos de rango inferior, parece ser en parte consistente con la hipótesis de una pervivencia inicial de divisiones administrativas anteriores, tal vez las diocesis y territoria de tradición visigoda a las que la documentación escrita hace alusión como unidades de recaudación. Sin embargo, al menos desde mediados del siglo VIII, parece que debió empezar a establecerse un sistema provincial $a d$ hoc que unificaría varios de estos $a^{\prime} m \bar{a} l$ limítrofes en una única región administrativa, la $k \bar{u} r a^{45}$. Se trata, sin embargo, de una reorganización que tuvo una implantación efectiva en los territorios más cercanos a Córdoba, pero que no parece aplicarse en la frontera ${ }^{46}$, que siguió oscilando entorno a los $a^{\prime} m \bar{a} l$ y los $a h w \bar{a} z$ de forma generalizada, si atendemos al ejemplo de Tortosa o el resto del valle del $\mathrm{Ebro}^{47}$.

\footnotetext{
${ }^{40}$ RACGG, pp. 303-304, 514-515; Negre 2013b.

${ }^{41}$ Flors 2010, pp. 207-215; Negre 2013b.

${ }^{42}$ UM, p. 163; TKS, ed. de al- 'Aț̣ār, bio. 2176; La primera identifica una fortaleza a partir del nombre de su territorio; la segunda, posterior, tan solo indica la existencia de un lugar con este nombre que es dependiente de $A b \bar{\imath} \bar{s}$ a (Orpesa). La fortaleza de Miravet (Cabanes, Castelló), documentada des del siglo XI, el castillo de Albalat (Cabanes, Castelló), aún sin datos arqueológicos, o incluso la propia $A b \bar{\imath} \breve{s} a$-solo para la primera noticia- son algunos candidatos a corresponderse con estas dos menciones, que no tienen por qué ser coincidentes.

${ }^{43}$ Flors 2010, p. 532.

${ }^{44}$ Selma 2014, p. 232; Negre, Lozano, Selma 2018; Selma, Negre, Lozano en prensa.

${ }^{45}$ MII/1, ed. Makkī, pp. 94, 99, 116, 438-440; MII/2, pp. 271-272; BML, II, pp. 111-112; Mu'nis 1957; Vallvé 1986; Meouak 1995.

${ }^{46}$ MII/1, ed. Makkī, p. 460.

${ }^{47}$ MII/1, ed. Makkī, p. 121; MII/2, pp. 6, 332; MIII, ed. Martínez Antuña, p. 87; Manzano 2006, pp. 430-431.
} 
Al mismo tiempo, estos distritos más alejados de la capital parecen haber estado identificados en distintos momentos a lo largo del emirato bajo la denominación de $\underline{t} u \dot{g} \bar{u} r$ (sing. $\underline{t} a \dot{g} r$ ). Bajo este término se designaron zonas periféricas, de naturaleza móvil, en linde con regiones no-musulmanas ( $D \bar{a} r$ $a l$-harb), susceptibles de ser atacadas. Estas mismas características pueden extrapolarse también a las zonas costeras siendo, tanto las unas como las otras, objeto de atención preferencial por parte del Estado ${ }^{48}$. El caso de la frontera de Barcelona y Tortosa es especialmente significativo, puesto que se trata de regiones expuestas a hostigamiento tanto terrestre como marítimo. Antes de la caída de Barcelona, esta zona es descrita como el extremo de la frontera oriental de los musulmanes (qāṣiyyat țag̉r al-muslimīn al-šarqiyya ${ }^{49}$. De la misma manera, la descripción más antigua de que disponemos para Tortosa, realizada a finales del siglo IX, la identifica como la última frontera de alAndalus al oriente, linde con el país de los francos (Ifranğiyūn) y sobre el mismo río que Zaragoza ${ }^{50}$. Las gentes de esta ciudad, asimismo, son consideradas como parte integrante de un espacio fronterizo como mínimo desde la caída de Barcelona, en $801^{51}$. En cualquier caso, estas menciones más antiguas sugieren un concepto de frontera amplio, que no identificaría territorios con límites precisos sino un espacio en conflicto (t tag $r$ al-Andalus ${ }^{52}, \underline{t} u g \bar{u} r^{53}$, al-ațrāf $\left.w a-l-\underline{t} u g \bar{u} r^{54}\right)$.

En resumen, durante los dos primeros siglos de al-Andalus se intuyen ya dos tendencias desiguales: en los lugares más cercanos a la capital, el progresivo abandono de las divisiones heredadas y su sustitución por circunscripciones provinciales delimitadas en función de los intereses andalusíes, las kuwar (sing. küra); en las fronteras, por el contrario, el mantenimiento de las circunscripciones urbanas o a $m \bar{a} l$ como marco territorial y el uso genérico del concepto ta $a \dot{g} r$ para identificar el límite de Dār al-Islām, sin que se desprenda una aplicación administrativa del mismo.

${ }^{48}$ Chalmeta 1991, p. 16.

${ }^{49} \mathrm{MII} / 1$, ed. Makkī, p. 116.

${ }^{50} \mathrm{~KB}, \mathrm{p} .355$.

${ }^{51}$ Durante el último de los asedios de los ejércitos carolingios a la ciudad de Tortosa (808-809), parte de sus defensores son descritos como ahl al-tagr (BML, II, p. 74), mientras que una acción ofensiva posterior contra Terrassa (856-857) es encabezada por la leva de las fronteras, entre la que probablemente se encontraba la gente de Tortosa (hašd al-tugi $\bar{u} r$ ) (BML, II, p. 98).

${ }^{52}$ FM, p. 208; KB, p. 354.

${ }^{53} \mathrm{MD}$, ed. Barbier, Pavet, vol. I, pp. 359-367.

${ }^{54}$ IS, vol. II, p. 111. 


\subsection{La descentralización de la frontera reflejada en su actividad} militar

En la Tortosa de los siglos VIII y IX, como debió suceder en otros puntos del litoral andalusí, una parte considerable de las acciones bélicas se desarrollaron en el ámbito naval ${ }^{55}$. Es al-Himyarī el autor que mayor información ofrece sobre los vínculos de los habitantes de la desembocadura del Ebro con las incursiones marítimas. En un primer texto afirma que las costas tortosinas fueron el lugar desde donde zarpó en el 829 una importante expedición andalusí que colaboró activamente con los Banū l-Ag̉lab en la conquista de Sicilia ${ }^{56}$, mientras que en una segunda noticia narra el papel de un grupo de marineros andalusíes (bahriyyūn) en la fundación de Pechina durante los últimos años del emir Muḥammad (852-886) ${ }^{57}$.

El relato inicial, en el que se describe el ataque del 829 contra Sicilia, trae a la memoria otras incursiones navales que salieron de al-Andalus y afectaron diferentes islas y costas del Mediterráneo entre finales del siglo VIII y la primera mitad del siglo IX. Dentro de este grupo se deben incluir las expediciones de Mallorca y Menorca (798), Islas Baleares (799), Córcega (806), Pantelleria (806), Cerdeña y Córcega (807), Córcega (809), Cerdeña y Córcega (810), Córcega (810), Cerdeña (812), Mallorca (813), Civitavecchia y Niza (813), Alejandría (815) y Mallorca y Menorca (848) ${ }^{58}$.

En cuanto al segundo de los textos, el autor árabe nos cuenta que los bahriyyūn pertenecían a los estratos más bajos de la sociedad, habitaban mayoritariamente en Tortosa y se dedicaban al transporte naval de personas, al comercio de productos diversos, incluyendo los bienes de lujo, y al saqueo de las costas latinas ${ }^{59}$. Al parecer, antes del 875 se asociaron y decidieron violar las normas de navegación que habían legislado los emires omeyas, hasta el punto que atacaron Marchena, dentro del territorio andalusí. Como consecuencia de este acto debieron exiliarse por miedo a las represalias, y no regresaron a la Península hasta que la generalización de las revueltas les puso en

\footnotetext{
${ }^{55}$ Sobre la actividad marítima de los andalusíes y las incursiones navales de ese período, véanse los siguientes trabajos: Aguadé 1976; Guichard 1979, 1983; Lirola 1993, pp. 94-95, 107-109, 122-123, 137-150; Ballestín 1999, en prensa; Picard 2007, pp. 414, 426-429, 437-443. p. 66.

${ }^{56}$ KR, ed. 'Abbās, p. 429; BML, I, pp. 96-97; Lirola 1993,pp. 107-109, 138; Ballestín 1999,

${ }^{57} \mathrm{KR}, \mathrm{pp} .79-80$.

${ }^{58}$ ARF, pp. 104-105, 108-109, 122, 124, 128, 130, 133, 137, 139; MII/2, pp. 2-3; Aguadé 1976, pp. 162-165; Guichard 1983, pp. 60, 62-63.

${ }^{59} \mathrm{La}$ importancia del fenómeno baḩriyyūn en Tortosa no implica que fuera exclusivo de aquella región (MII/1, ed. Makkī, p.456; MII/2, pp. 2-3, 308-309, 353, 398; BML, II, p. 106).
} 
una posición ventajosa ante el emir. Sin embargo, ya no volvieron a Tortosa, sino que se instalaron en Pechina ${ }^{60}$.

Las coincidencias evidentes que se observan en los dos relatos recogidos por al-Himyarī podrían llevar a pensar que fueron los bahriyyūn, por sí mismos, y sin la ayuda de otros grupos o instituciones, quienes realizaron la incursión del 829. No obstante, existen dos motivos por los cuales resulta improbable que las gentes de mar actuaran solas en las grandes expediciones navales. Por un lado, la necesidad de huir de al-Andalus tras el ataque contra Marchena es poco compatible con la hipotética capacidad autónoma de organizar una flota de 300 embarcaciones $^{61}$, y por el otro, el único texto que describe de manera parcial como se organizaba este tipo de incursiones muestra una realidad más compleja. En efecto, Ibn Haldūn narra como la conquista definitiva de Mallorca (903) fue debida a la colaboración entre el emir 'Abd Allāh (888-912) y la iniciativa privada de un devoto y rico musulmán, 'Ișām al-Hुawlānī. Ambos prepararon embarcaciones y reclutaron hombres que quisieran hacer el ğihā $d^{62}$, aunque la dirección de la expedición quedó únicamente en manos del segundo. 'Abd Allāh le recompensaría nombrándole gobernador de la isla tras el éxito de la operación ${ }^{63}$. Esta noticia pone de relieve la relación entre bahriyyūn, sin los cuales no se podrían tripular las naves, voluntarios del ğihād, como parecen serlo 'Ișām al-Hुawlānī y los combatientes alistados, y poder público, en este caso el emir de Córdoba.

En nuestro caso de estudio, la presencia en Tortosa de muğāhidūn que pudieran participar en estas expediciones navales durante la primera mitad del siglo IX está confirmada por la existencia del ribăt Kašk $\bar{l}$, sobre el cual ya hablaba el alfaquí 'Abd al-Malik b. Habīb (m. 852) ${ }^{64}$. Más problemas genera, por el contrario, la participación del poder central cordobés en esas expediciones. Vuelven a ser dos los argumentos que se pueden aducir para dudar de su intervención directa en las actuaciones de este tipo durante aquel período. El primero de ellos es la inexistencia de una flota regular omeya antes del $844^{65}$. El segundo, y más importante, es la diferencia entre los

${ }^{60}$ KR, pp. 79-80; Lirola 1993, pp. 122-123, 137-150, 389-392; Ballestín 1999, pp. 66-67, en prensa, p. 34.

${ }^{61}$ BML, I, pp. 96-97.

${ }^{62}$ Ibn Hawqal también calificó de muğāhidūn a los ocupantes musulmanes de Fraxinetum, enclave situado en la costa provenzal que había sido tomado por los andalusíes tras una incursión naval (KSA, ed. Beirut, pp. 174-175; ANT, pp. 275-276; Ballestín en prensa, pp. 69-70, 74-75).

${ }^{63} \mathrm{TI}, \mathrm{IV}, \mathrm{p} .210$.

${ }^{64}$ KGZ, pp. 90, 103. Sobre la práctica del ribāt: Marín 2004. Sobre el ribāṭ Kaškī: Negre 2015, pp. 116-120.

${ }^{65}$ MII/1, ed. Makkī, p. 456; Lirola 1993, pp. 113-114. 
ingresos fiscales del emir de Córdoba y el coste de organizar una expedición militar. El valor anual de la recaudación era de 600.000 dinares en tiempos del emir al-Ḥakam (796-822) y de un millón con su hijo 'Abd al-Raḥmān $(822-852)^{66}$, mientras que el precio de preparar una aceifa podía superar los 500.000 dinares $^{67}$. Si a estos datos añadimos el hecho que hay años, como en el 806 , el 809 , el 810 y el 813 , donde se documentan dos, tres y hasta cuatro incursiones por año $0^{68}$, la idea que emerge es que una parte muy importante de la financiación de guerra andalusí no iría a cargo del poder central. Este esfuerzo bélico que no podía ser cubierto por el emir omeya debía ser sufragado por sus delegados a nivel local.

No faltan datos donde se aprecia cómo los gobernadores provinciales del emirato se quedaban con gran parte de los ingresos fiscales recaudados en sus distritos y los utilizaban entre otras finalidades para mantener a sus propias tropas ${ }^{69}$. La fuente que más información nos aporta al respecto en nuestro territorio es una carta que el gobernador de la ciudad de Tortosa, 'Ubayd Allāh b. Yaḥyà, escribió al emir 'Abd al-Raḥmān b. al-Ḥakam en el año $850 / 851^{70}$. En ella, el gobernador expone la situación de sus dominios después de obedecer la orden de Córdoba de apoyar militarmente la rebelión contra los carolingios de Guillem, hijo de Bernat de Septimania, en el año $849^{71}$. Además, informa de que ya no necesitaba de las fuerzas cordobesas (hurs) y que se bastaba con el contingente de 130 hombres de que disponía, formado por sus propios clientes (mawāl $\bar{\imath})$ y sirvientes ( $\dot{g} i l m \bar{a} n)$. Además, se menciona con claridad que el mantenimiento de estas tropas locales, mediante concesiones territoriales (qata ${ }^{\prime} i$ ), corría a cargo de los bienes del Estado ( $m \bar{a} l$ al-sultān) que estaban bajo su control. Finalmente, describe como de la recaudación de los tributos de su demarcación (min ğibāyat 'amali-hi), entre los que incluye las $\breve{g} i z \bar{a}^{\prime}$ cristianas y los 'ušūr musulmanes, se podían pagar no solo el mantenimiento de las fortalezas y las estructuras de la frontera sino también 200 dinares mensuales como emolumentos de sus agentes fiscales (li- 'ummālati-hi) y 1.000 dinares anuales como propios del gobernador. Si

\footnotetext{
${ }^{66} \mathrm{MII} / 1$, ed. Makkī, p. 292; NT I, p. 348.

${ }^{67}$ Este era el coste de hacer una expedición de verano en tiempos del hăăğib al-Manșūr (9781002) (KA, p. 98).

${ }^{68}$ En el 806 se produjeron las expediciones andalusíes de Córcega y Pantelleria, en el 809 las de Córcega y Pirineo aragonés, en el 810 las de Guadalajara, Cerdeña y Córcega, y Córcega una vez más, y en el 813 las de Muhammad b. al-Hakam, Barcelona, Mallorca, y Civitavecchia y Niza (ARF, pp. 122, 124, 128, 130, 133, 139; MII/1, ed. Makkī, pp. 136-137, 231-232; BML, II, p. 75-76).

${ }^{69}$ Manzano 1991, pp. 330-331, 2011, pp. 341-344.

${ }^{70} \mathrm{MII} / 2$, pp. 6-7.

${ }^{71}$ Ibidem, p. 3.
} 
bien parece probada la lealtad de este último hacia el Estado omeya, dentro del cual ejercerá cargos de alta jerarquía como el de $\operatorname{visir}^{72}$, es significativa la amplia independencia de la que parece gozar en la administración de sus territorios y de las recaudaciones fiscales vinculadas a él.

Así mismo es posible encontrar varios ejemplos en los cuales se pone de relieve la relación entre las autoridades locales y los miembros que participaban en estas incursiones. Aunque se pueden hacer algunas matizaciones, el comienzo de los grandes ataques marítimos de finales del siglo VIII y principios del IX coincide en el tiempo con la formación de un poder autónomo en el Šarq al-Andalus ${ }^{73}$. En los momentos previos al asedio de Barcelona por los carolingios (801), el gobernador árabe de la ciudad contaba entre sus habitantes con ladrones Maurorum que saqueaban el sur de la Galia y recibían riquezas a través de los barcos que atracaban allî4 . Y cuarenta años después, en el 848, el emir 'Abd al-Raḥmān b. al-Hakam envió uno de sus eunucos al gobernador de Valencia para que extrajese el quinto del botín tras el triunfo de la flota musulmana sobre los habitantes de las Islas Baleares ${ }^{75}$. Todo parece indicar, así pues, que el elemento público que principalmente apoyó las expediciones navales fue el gobierno local de las provincias costeras. Y quizá sea este el motivo por el cual estas son mayoritariamente ignoradas por los compiladores árabes, quienes habitualmente tomaban como fuente las crónicas elaboradas en el entorno cortesano de los omeyas ${ }^{76}$.

Esta realidad descentralizada que se observa en las incursiones marítimas de los siglos VIII y IX todavía resulta más clara cuando se estudian los contingentes andalusíes que tomaron parte en la lucha contra los territorios cristianos. Las crónicas conservadas son especialmente generosas a la hora de nombrar las tropas andalusíes que defendieron Tortosa del último ataque carolingio contra esa ciudad (808-809). Según la información de las diferentes versiones, en los combates que se libraron participaron cives, ğunüd, ahl altagigr, hušūd y muțtawwi 'a.

- Los cives serían los habitantes de Tortosa, quienes en el momento más álgido de lucha tendrían bajo su responsabilidad las llaves de la ciudad, lo cual sugiere un control sobre el recinto amurallado ${ }^{77}$.

${ }^{72} \mathrm{MII} / 2$, p. 168.

${ }^{73}$ Guichard 1983, pp. 59-62.

${ }^{74} \mathrm{EN}$, pp. 12-15, 22-27, 30-31.

${ }^{75} \mathrm{MII} / 2$, ed. Makkī, pp. 2-3.

${ }^{76}$ Guichard 1983, p. 61; Viguera 1997, pp. 5-6.

77 VHI, pp. 330-331. La participación bélica de los habitantes de las ciudades (ahl almadīna) y de las fortalezas rurales (ahl al-ḥușūn) en la defensa de sus hogares está ampliamente 
- Los $\breve{g} u n \bar{u} d$ (sing. $\breve{g} u n d$ ) son tropas regulares que reciben un salario público ${ }^{78}$. En este enfrentamiento habrían combatido los ğunūd enviados por el emir de Córdoba y aquellos que estaban bajo las órdenes de los gobernadores de Tortosa, 'Ubaydūn b. al-Ġamr, y Zaragoza, 'Amrūs b. Yūsuf ${ }^{79}$. La posterior rebelión de 'Amrūs contra el poder cordobés y el ejemplo mencionado de la carta de 'Ubayd Allāh b. Yahyà, donde se observa como el gobernador de Tortosa mantenía con los bienes del Estado una guardia personal formada por 130 de sus mawāl $\bar{l}$ y gilmā $n^{80}$, indicarían que estos $\check{g} u n \bar{u} d$ fronterizos estaban financiados por las autoridades locales, a diferencia de los primeros, y que, en consecuencia, su lealtad iba especialmente dirigida a ellas.

- El ahl al-tagir son los habitantes de la frontera reunidos por los gobernadores de Zaragoza y Tortosa tras recibir la orden omeya de unirse al ejército salido de la capital ${ }^{81}$.

- El hašd (pl. hušūd) es un concepto ambiguo utilizado por los cronistas árabes normalmente para designar alistamientos fronterizos o levas de tropas no profesionales ${ }^{82}$. En este caso concreto, la orden que previamente había dado el emir al-Hakam de movilizar a los habitantes de la frontera apoya la idea que es el resultado de una leva fronteriza ${ }^{83}$.

- Los muttawwi 'a, por último, son tropas irregulares que no reciben un sueldo público por su intervención en las campañas militares ${ }^{84}$. Ibn Hayyān afirma que estaban a cargo de los gobernadores de Zaragoza y Tortosa ${ }^{85}$, una circunstancia que sugiere

documentada durante la fase del emirato (756-929) (MII/1, ed. Makkī, pp. 451, 453; MII/2, p. 396; TA, pp. 37, 38, 42; BML, II, p. 145; MV, pp. 62-63, 81-82, 83, 94, 105).

${ }^{78}$ Chalmeta 1976, pp. 411-412; 1988, pp. 35-36; Manzano 1993; Meouak 1993, pp. 365-368; Viguera 2001,pp. 27, 29-30.

${ }^{79}$ En la edición facsímil de Ibn Ḥayyān leemos ğunūd en vez de ğund cuando se hace referencia a las tropas regulares comandadas por los gobernadores fronterizos (MII/1, ed. Vallvé, f. 100v; MII/1, ed. Makkī, p. 132; BML, II, p. 74).

${ }^{80} \mathrm{MII} / 1$, ed. Makkī,pp. 133-134; MII/2, pp. 6-7.

${ }^{81}$ BML, II, p. 74.

${ }^{82}$ Casos donde $h a s ̌ d / h u s ̌ \bar{u} d$ parece hacer referencia a tropas fronterizas: MII/1, ed. Makkī, pp. 103, 121, 420; MII/2, pp. 304, 325; BML, II, pp. 98, 106, 144, 177, 180, 195; MIII, ed. Martínez Antuña, pp. 134-135; TA, p. 66; MV, p. 94; MVII, p. 227. Ejemplos de hašd/hušūd con el significado de tropas no profesionales en oposición a los efectivos del ejército regular: MII/1, ed. Makkī, p. 428; MV, pp. 105, 122, 295, 299; BML, II, pp. 184, 196.

${ }^{83}$ BML, II, p. 74.

${ }^{84}$ Chalmeta 1976, pp. 414-415; Meouak 1993, pp. 369-370; Aguilar 1997, p. 196; Molénat 2005, p. 555; Viguera 2001, pp. 27-28.

${ }^{85}$ MII/1, ed. Makkī, p. 132; BML, II, p. 74. 
una presencia en la frontera antes de la llegada de las tropas cordobesas. Este hecho, y la conocida participación entre sus miembros de ulemas y creyentes musulmanes dispuestos a sacrificar bienes y vidas por el Islam ${ }^{86}$, vinculan a estos efectivos con los practicantes del ribāt. Tampoco se puede descartar, no obstante, que con este concepto se esté haciendo referencia a los miembros de la anterior leva fronteriza que no eran tropas regulares ${ }^{87}$.

Al margen de las dificultades que provoca la correcta interpretación de alguno de estos términos, la conclusión que se obtiene después de este análisis es la del mayor peso del elemento local en la defensa de Tortosa. Aunque $\check{g} u n \bar{u} d$ fronterizos, ahl al-taggr y hušū $d$ pudieran aludir en realidad a un mismo contingente mencionado de diferentes maneras por los distintos compiladores, la suma de este con los cives y los mutțawwi 'a supera la aportación del poder central, que sólo habría estado representado con los ğunūd enviados por el emir.

Idéntica situación es la que se encuentra en otro de los sucesos bélicos que tiene relación con la frontera de Tortosa. Muhammad b. 'Abd al-Malik al-TTawīl, gobernador de Huesca, lanzó un ataque contra Barcelona, en el año 913, como respuesta probablemente a los progresos condales en el Penedès ${ }^{88}$. Antes de partir en campaña hizo alistamientos en la frontera (hašada), y en el combate que le costó la vida pereció también su guardia personal $(h \bar{a} s \underline{s} a)^{89}$, un contingente que vuelve a traer a la memoria los 130 mawālī y gilmān de 'Ubayd Allāh b. Yahyàa ${ }^{90}$. De lo visto hasta ahora se puede afirmar que la relativa autonomía administrativa de las ciudades fronterizas, los limitados ingresos fiscales del poder central, la organización de buena parte de las operaciones militares y la naturaleza de los contingentes armados que protegían la frontera muestran un Estado que en muchos aspectos debe ser considerado como profundamente descentralizado.

\footnotetext{
${ }^{86}$ MVII, p. 226; BML III, p. 4.

${ }^{87} \mathrm{MII} / 2$, pp. 271-273; MV, pp. 304-305.

${ }^{88}$ La expedición habría tenido como principal objetivo "reparar las brechas de la muralla de Tortosa y sostenerla" (TA, p. 66).

${ }^{89}$ Ibidem.

${ }^{90} \mathrm{MII} / 2$, pp. 6-7.
} 


\section{HACIA UN NUEVO MODELO DE ESTADO: LAS REFORMAS DE 'ABD AL-RAHMMĀN AL-NĀṢIR}

La división provincial andalusí recogida por las fuentes árabes queda completamente estandarizada durante el califato bajo los dos tipos de circunscripción a los que ya hemos hecho referencia: la küra, principalmente identificada en las áreas alejadas de la frontera y el 'amal o circunscripción urbana, que predomina en los sectores en linde con los territorios cristianos ${ }^{91}$. Además, el uso del término tag $r$ se vuelve cada vez más habitual en las fuentes escritas de este período, sin que de ello se desprenda que se trate de marcos administrativos que sustituyeran a los $a^{\prime} m \bar{a} l^{92}$. Es a Ibn Hayyān a quien debemos la sistematización de estas regiones, ya en el siglo XI, y a partir del cual la historiografía ha construido un relato sobre su uso como unidades geopolíticas contrapuestas a las kuwar ${ }^{93}$. Un planteamiento que, como analizaremos a continuación, no compartimos. Estas demarcaciones fronterizas, con funciones de control y actuación militar, identifican entonces el espacio de acción de una

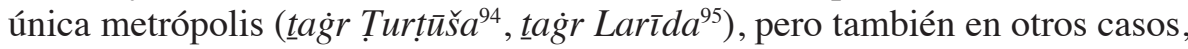
marcos geográficos más amplios y muchas veces superpuestos entre sí (altagr al-aqșă ${ }^{96}$ o al-a là ${ }^{97}$, al-tagr al-awsaț ${ }^{98}$ y al-tagr al-adnà $\grave{19}^{99}$, de norte a sur, o al-țagr al-šarq $\bar{\imath}^{100}$, al-tagr al-ğawf ${ }^{101}$ y al-tagr al-garb $\bar{\imath}^{102}$, de este a oeste ${ }^{103}$ ).

\footnotetext{
${ }^{91}$ AMA, pp. 39-58; KSA, ed. Kramer, pp. 108, 203; MV, pp. 242-245, 265; MVII, pp. 68-69; al- 'Uḍrī, ya en el siglo XI, define como küra a Zaragoza, dándole un papel central en su explicación de las fronteras del valle del Ebro (a las cuales, por cierto, nunca denomina como al-tagr al-a là). No usa este término, en cambio para otras circunscripciones de esta región, como Tortosa, Lleida o Huesca, que son considerados como ciudades o a 'māl (Granja 1966).

${ }^{92} \mathrm{MV}$, pp. 127, 167, 307-308, 324, 329, entre otros; MVII, pp. 68-69, 151-152, 168-169, entre otros.

${ }^{93}$ Chalmeta 1991, p. 16.

${ }^{94}$ MV, p. 167.

${ }^{95} \mathrm{MV}$, p. 326.

${ }^{96}$ MII/1, ed. Makkī, p. 221; MV, pp. 94, 106, 121, 218, 258, 307, 316.

${ }^{97}$ MII/1, ed. Makkī, pp. 94-97, 101, 104-105, 108, 110, 119-121, 133-139, 149, 152, 189 , 220-222, 225, 289, 396, 422 , 429, 446-447, 450, 460, 463; MII/2, pp. 315-316, 326, 328, 331333, 392; MIII, ed. Makkī, pp. 56, 58, 61, 162-164, 215; MV, pp. 65, 83, 96, 107, 120-127, 131, 167, 190-191, 241-245, 256-257, 266-268, 276, 279, 296, 307, 316-317, 324-326.

${ }^{98}$ MII/1, ed. Makkī, p. 302; MIII, ed. Makkī,,p. 61; MV, pp. 102, 267, 279, 286. 273.

${ }^{99} \mathrm{MII} / 2$, pp. 18, 316; MIII, ed. Makkī, pp. 154, 237-239, 241, 244; MV, pp. 218, 258, 267,

${ }^{100}$ MII/1, ed. Makkī, pp. 116, 131; MV, pp. 127, 306, 308.

${ }^{101} \mathrm{MV}$, pp. 102, 306, 309-310.

102 MV, pp. 293, 306.

${ }^{103}$ Lorenzo en prensa.
} 


\subsection{Entre la organización fiscal y la defensa de Dār al-Islām}

En el caso de Tortosa, Ibn Hayyān muestra una coexistencia de facto entre distrito administrativo y zonificación fronteriza, al describir los dominios de la ciudad como un ' $a m a l^{104} \mathrm{y}$ al mismo tiempo como parte de al-țugūr $a l$-šarqīyya ${ }^{105}$. A pesar de esta dualidad, a partir del califato se detecta un cambio importante en el valle del Ebro: la diferenciación progresiva entre el área controlada por Tortosa, en el extremo oriental de las fronteras, y la de Zaragoza, en la frontera superior ${ }^{106}$. No existe vacilación tampoco en las fuentes árabes a la hora de incluir Lleida en el extremo oriental de esta última área (qạsisyyat al-țagr al-a 'là), algo que no se observa nunca más en el caso de Tortosa ${ }^{107}$. Esta tendencia a separar ambos espacios parece acentuarse a partir del año 929, cuando 'Abd al-Raḥmān al-Nāșir, ya intitulado como califa, empieza a nombrar nuevos gobernadores para las circunscripciones fronterizas, distinguiendo claramente entre el control de Tortosa y el de Lleida y Zaragoza $^{108}$.

En este sentido, en el año 929 se produjo el nombramiento de 'Uțmān b. 'Ubayd Allāh b. Muhammad b. Abī 'Abda como gobernador de Tortosa y su frontera ${ }^{109}$, al que siguieron una amplia lista de nombramientos con la intención de reafirmar la adhesión de esta ciudad a Córdoba ante diversos alzamientos contra el califa en la frontera superior ${ }^{110}$. Se reafirma aún más esta preponderancia si atendemos a la noticia del nombramiento de Abū Sa 'd 'Abd al-Mu'min b. Yazīd al-Anșārī (m. 943) como jefe de la plegaria (șāhị al-șalāt) para la capital (hādira) de Tortosa ${ }^{111}$, lo que confirió a la urbe una jerarquía de la que no tenemos constancia que hubiese gozado hasta ese momento $^{112}$. Esta progresiva adquisición de una identidad fronteriza propia, sin depender de las instrucciones de Zaragoza, parece también intuirse en un pasaje de Ibn Ḥayyān referente al año 939, en el que separa con claridad las

${ }^{104}$ MV, p. 265; en un momento posterior, durante el gobierno de al-Hakam, llega a describírsela también como parte de las kuwar al-šarq (MVII, p. 216), aunque no puede saberse si esta mención única corresponde a un término genérico para describir los territorios de las regiones orientales de al-Andalus o si realmente se trata de un cambio en su estatus administrativo. Desde nuestro punto de vista, optamos por la primera opción.

${ }^{105}$ MV, pp. 307-308; Antes de ello, el cronista cordobés también había identificado la ciudad como parte de al-tagr al-a là (MII/2, p. 6; MIII, ed. Martínez Antuña, p. 52).

${ }^{106}$ MV, p. 127.

${ }^{107}$ MV, p. 324; TA, pp. 72-73; MVII, pp. 68-69, 151-152, 168-169.

${ }^{108}$ MV, p. 213; KTI, pp. 112, 123.

${ }^{109}$ MV, p. 167.

${ }^{110}$ Ibidem, pp. 190, 241, 256-257, 265, 275-276, 291, 314.

111 TKS, ed. de al- 'Atțār, bio. 877.

${ }^{112}$ Ballestín 1994,p. 57. 
fronteras superior y oriental al citar la orden de algarabía del califa a todos los $q u w w \bar{a} d$ (sing. $q \bar{a}$ 'id) y 'ummāl (sing. 'āmil) de las regiones fronterizas ${ }^{113}$.

A las designaciones mencionadas hay aún que añadir la de Mundir b. Sa 'îd al-Ballūṭī, en 942, como cadí supremo de todas las fronteras, con la función de supervisar a todos sus cadíes y gobernadores, y ejercer como inspector de quienes llegaran de territorios cristianos ${ }^{114}$. Este importante cargo, documentado por primera vez en este momento y con base en Tortosa ${ }^{115}$, muestra una clara relación de correspondencia entre la capital cordobesa y esta ciudad. Pensamos que también apuntan en esta misma dirección la identificación de diversos alfaquíes provenientes de la frontera oriental entre 950$1050^{116}$, o la judicatura, en tiempo de los amiríes, de Abū al-Aṣbag Mūsà sobre Ṭurțūša, Balansiya, Undāra, Mayūrqa, Manūrqa y Yābisa ${ }^{117}$.

Otro argumento a favor de esta propuesta lo conforman el conjunto de quwwād documentados en las fuentes árabes ejerciendo su autoridad desde Tortosa. El cargo de $q \bar{a}{ }^{\prime} i d$, como cabeza principal de uno de los ejércitos del califa, resultaba clave en el entramado de poderes de la frontera, pues era la figura primera encargada de la defensa y, en ocasiones, de la organización de las circunscripciones de los țugūr. Uno de los ejemplos más claros nos lo ofrece el gobernador 'Abd al-Raḥmān b. Muhammad b. al-Naẓāām -nombrado en 940 - quien, ya bajo el cargo de $q \bar{a} ' i d$ y por orden del califa, mandó construir el arsenal de la ciudad y unas nuevas murallas en el año $945^{118}$. Estas obras se complementarían con la construcción de una gran mezquita de cinco naves con un amplio patio delantero, terminada en el año 956, y probablemente también con unos baños para los que se trajeron piezas realizadas en alabastro en los talleres de al-Madīna al-Zahrā' ${ }^{\prime}$, una de las cuales está fechada entre los años 960 y $961^{119}$.

Se trata de nombramientos persistentes, a tenor del enterramiento en la alcazaba de la ciudad de otro $q \bar{a}$ 'id, 'Abd al-Salām b. 'Abd Allāh b. Basīi -cuya muerte se produjo en el año $961^{120}$ - o del papel jugado pocos años después por el también $q \bar{a}$ 'id de Tortosa, Hišām b. Muhammad b. 'Uțmān, que actuó como escolta de Ènyec Bonfill, vicario del conde Borrell de Barcelona,

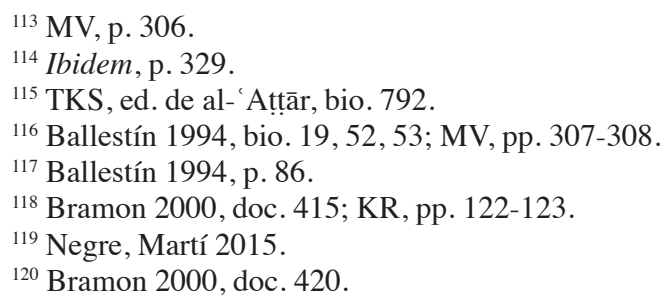


en su embajada a la ciudad de Córdoba ${ }^{121}$. Es posible que también podamos añadir a esta lista a Ahmad b. Ya là b. Wahb, quien en el año 964 defendió la ciudad del asedio prolongado (tūl al-muhāssarati) que el conde Borrell de Barcelona mantuvo sobre la misma ${ }^{122}$. Consta la muerte de este personaje en el año 972 en Zaragoza, ostentando los cargos de visir y $q \bar{a}$ 'id de dicha ciudad ${ }^{123}$, por lo que es plausible pensar que este mismo título sería el que ostentaría durante la defensa del asedio.

Cabe inferir, por tanto, que Tortosa y su área fronteriza adquirieron durante el califato una importancia significativa, siendo uno de los enclaves que pusieron freno a los hostigamientos cristianos, pero también al peligro fatimí, que acechó las costas hasta el traslado de su capital a la ciudad del El Cairo en el año 972.

Respecto a la organización de los a māa del tạg $r$, la información más precisa de la que disponemos se la debemos a al- 'Udrīi, quien recoge algunos casos ejemplares que permiten observar la división administrativa interna de estos territorios durante este período. La terminología que emplea este autor se basa en dos tipos básicos de distritos, descritos como aqālìm (sing. iqlīm) o $a \breve{g} z \bar{a}^{\prime}$ (sing. $\breve{g} u z^{\prime}$ ), siendo estos últimos inexistentes en las fronteras del valle del Ebro ${ }^{124}$. La definición de estos dos términos sigue siendo a día de hoy problemática, aunque los trabajos de Cressier en la Alpujarra ${ }^{125}$ llevaron a desestimar hipótesis previas que los vinculaban a la agricultura intensiva y a la ganadería, respectivamente ${ }^{126}$. Las fuentes son bien explícitas al identificar la adscripción de la gente a una determinada alquería (qarya), que a su vez se encuadraba en un iqlīm perteneciente a una demarcación provincial, bien una kūra, bien un 'amal'127. Se trataría, por tanto, de distritos sobre los que ejercería la autoridad un centro territorial secundario, habitualmente una fortaleza, que a su vez estaría bajo el control de la capital provincial.

De Zaragoza, al-'Uḍrī nos describe con claridad todos y cada unos de sus aqālìm, así como la relación de cada uno de ellos con una fortaleza o plaza central ${ }^{128}$, tal y como el mismo autor identifica en los 'ă̆zà de Elvira ${ }^{129}$ o en la combinación de ambos en el caso de Valencia ${ }^{130}$.

\footnotetext{
${ }^{121}$ MVII, pp. 3-6.

${ }^{122}$ IAG, vol. I, pp. 478-479.

${ }^{123}$ MVII, p. 38.

${ }^{124}$ TA, pp. $24-25$.

${ }^{125}$ Cressier 1984.

${ }^{126}$ Mu'nis, 1957; Barceló 1978.

127 Valor, Ramírez 2001, p. 265.

${ }^{128}$ TA, pp. 24-25; Granja 1966.

${ }^{129}$ Ibidem, pp. 90-91.

${ }^{130}$ Ibidem, pp. 19-20.
} 
Tortosa no ofrece dudas tampoco, y las fuentes mencionan que esta circunscripción está dividida en diferentes aqālīm, los cuales son citados siempre de forma global, sin mencionar cuales serían sus límites ni si existe alguna correspondencia con los $a h w \bar{a} z$ documentados anteriormente ${ }^{131}$. Para tratar de delimitar su número y extensión, proponemos acudir a una fuente relativamente tardía: el Uns al-muhağ wa-rawd al-fura $\breve{g}$ de al-Idrīsī, escrito a mediados del siglo XII. En ella, el geógrafo ceutí identifica hasta ocho ḥuṣūn (sing. hișn) dependientes de la ciudad de Tortosa, a los que aún habría que añadir un mínimo de cinco casos más mencionados en otros pasajes de la obra en relación a ciertos itinerarios ${ }^{132}$.

\subsection{El papel de los ḥuṣūn en la articulación de los aqā̄ìm}

La importancia que atribuimos a los hușūn en la restitución de la organización administrativa andalusí puede vincularse con el papel clave que las fuentes les otorgan en la articulación de la relación del Estado con sus dominios ${ }^{133}$. Controladas por encargados designados por el 'ámil o el $q \bar{a}$ ' $i d$ de la metrópolis y con guarniciones permanentes apostadas en ellas, estos enclaves servirían como elemento de penetración del Estado omeya en cada rincón de sus circunscripciones provinciales y ayudarían a organizar de forma más efectiva el control del territorio ${ }^{134}$. Si bien el elemento militar fue clave en el levantamiento de fortificaciones, la sujeción a control fiscal de las qurà (sing. qarya) de los aqālìm fue siempre su finalidad primordial. No se explica de otra manera que, de unas recaudaciones globales para el emirato de 'Abd alRaḥmān b. al-Ḥakam cercanas al millón de dinares anuales -y tras una bajada de los ingresos tributarios durante la crisis final del emirato- a mediados de la siguiente centuria ascendieran a más de seis millones por año ${ }^{135}$.

Pero, ¿de qué argumentos disponemos para poder hablar de un fenómeno generalizado de construcción de hușūn durante el califato en nuestro territorio? En primer lugar, cabe destacar que partimos de la imagen final de este proceso de edificación de fortalezas, que tras sucesivas fases acumulativas es descrita con precisión por al-Idrīsīi ${ }^{136}$. Su momento inicial, sin embargo, debe buscarse en indicios dispersos en fuentes escritas y arqueológicas. En relación

\footnotetext{
${ }^{131}$ MV, p. 190.

${ }^{132}$ UM, pp. 160-163; Martí, Negre 2014.

${ }^{133}$ Meouak 1995, pp. 183-184, 186-187.

${ }^{134}$ Manzano 2006, p. 437.

${ }^{135}$ MII/1, ed. Makkī, p. 292; NT, vol. I, p. 348; BML, II, p. 247; KA, p. 38.

${ }^{136} \mathrm{UM}$, pp. 160-163.
} 
a las primeras, cabe destacar la forma en que Ibn Hayyān se refiere a Tortosa durante el segundo cuarto del siglo X, donde constantemente hace mención a la ciudad, su frontera y sus distritos ${ }^{137}$. Por el contrario, este mismo autor, al referirse a Lleida, lo hace siempre mencionando la ciudad y sus fortalezas, dando un peso importante a las últimas ${ }^{138}$. Aunque no supone una prueba absoluta, esta diferencia a la hora de describir dos territorios tan cercanos, espacial y temporalmente, no puede sino llamar la atención sobre la aparente escasez de hușūn en uno de ellos con anterioridad al año 940.

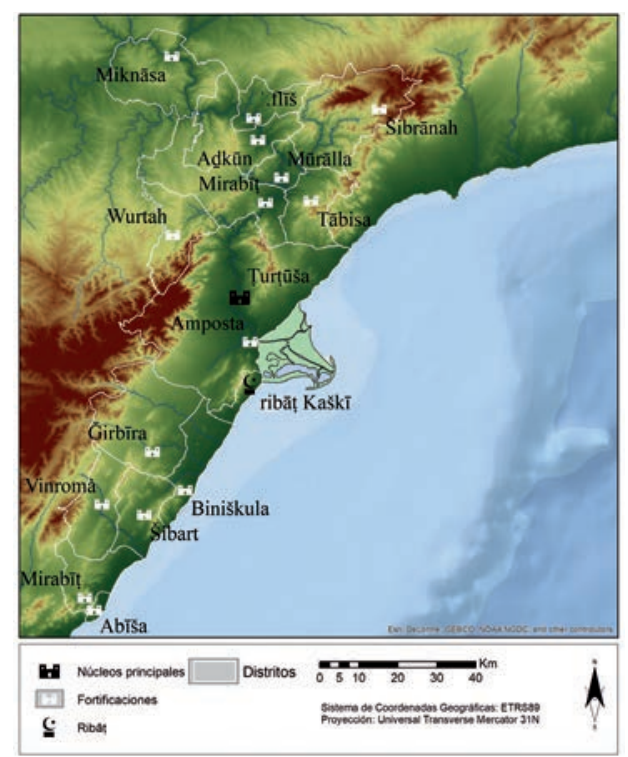

Fig. 2 Principales enclaves mencionados en el texto y propuesta de restitución de sus distritos (aqālìm), definidos a partir del uso combinado de la documentación árabe y latina medieval. Se incluye también el pequeño distrito del ribāt Kašk̄ tal y como es descrito por las fuentes latinas de finales del s. XI.

La zona del curso inferior del Ebro debió establecerse como área de $\underline{t} a \dot{g} r$ tras la caída de los territorios y fortalezas a poniente del Llobregat durante las primeras décadas del siglo $\mathrm{X}^{139}$, así como tras la pérdida de Tarragona el año $942^{140}$. No es de extrañar que, coincidiendo con esta última fecha, se

${ }^{137} \mathrm{MV}$, pp. 167, 190, 265.

${ }^{138}$ Ibidem, pp. 213, 256, 265, 291.

${ }^{139}$ Martí 1992, pp. 28-29; 2017; Gibert 2011,pp. 259, 420, 433, 441.

${ }^{140} \mathrm{MD}$, ed. Mar' 1 , vol. I, p. 126; El geógrafo oriental al-Mas 'ūdī informa que en el año 942 los andalusíes perdieron Tarragona (sic. Arbūna) junto con otras ciudades y fortalezas, quedando 
produjese la llegada de al-Ballūṭī a Tortosa para instalar allí una supervisión de las fronteras ${ }^{141} \mathrm{o}$ el intento de enviar una expedición marítima de castigo contra las costas cristianas bajo el mando de Muhammad b. Rumāhịis ${ }^{142}$. En este contexto, el califa debió ordenar el inicio de un proceso intensivo de fortificación a lo largo del curso fluvial, abandonando ya el área de difícil defensa del llano tarraconense para centrarse en la frontera del Ebro y la ciudad de Tortosa ${ }^{143}$. Al mismo tiempo, la retaguardia de esta zona fronteriza inició también un proceso de construcción paralelo, asegurando el control territorial y la sujeción fiscal de sus dominios.

Desde el extremo más alejado del río, en su cruce con el Cinca, tenemos constancia documental de la existencia en el siglo $\mathrm{X}$ de una pequeña fortaleza en Mequinenza (Zaragoza), inexistente a principios del siglo IX ${ }^{144}$. Más adelante, el ejemplo que más información nos aporta en este sector es el de Miravet (Tarragona), una fortaleza que ha sido excavada de forma sistemática durante las últimas décadas. Se han podido detectar dos fases andalusíes: una primera, de época califal, con pocos restos conservados, y una segunda, fechada a partir del siglo XI, que configura el recinto y que es amortizada tras la conquista ${ }^{145}$. Cabe destacar que se recuperó además un pequeño sello de bronce grabado, descontextualizado, que se atribuye a esta misma cronología. Su inscripción aún permite leer con dificultad el nombre de su dueño y su lema: 'Abd al-Mālik bi-Allāh yatiq, o "en Dios tiene confianza"146. Aún sin poder identificar claramente qué cargo ostentaba en la fortaleza, un elemento singular de estas características nos está confirmando la presencia de una figura de autoridad vinculada al funcionamiento de la misma.

\footnotetext{
como límites de la frontera con los francos Tortosa, Fraga y Lleida. La noticia puede parecer dudosa por el hecho que el volumen V del Muqtabas termina su narración en ese mismo año y no hace mención de esta importante pérdida. Esta omisión podría deberse, simplemente, a que la noticia en cuestión esté incluida en el volumen VI, aún desaparecido. Sin embargo, hay dos factores que, desde nuestro punto de vista, dan validez a la noticia: en primer lugar, el ataque que en el año 943 una flota omeya de treinta y seis navíos realizó contra las costas francas (TA, p. 81), muy probablemente como respuesta al avance condal; y en segundo lugar, las dos embajadas catalanas de 953 y 966, en las que los sucesores del conde Sunyer de Barcelona incluyeron en su titulatura la ciudad de Tarrakūna, una circunstancia que no se había producido con anterioridad (TI, vol. IV, pp. 184, 187; NT, vol. I, pp. 366, 384-385). La ocupación de este territorio no fue definitiva, pues en las distintas expediciones de al-Manșur contra Barcelona en 978, 982, 984 y 985 (TA, pp. 75, 78-80; IAG, pp. 105-106; KA, pp. 74, 99), en especial la última, debió expulsarse a cualquier contingente que hubiese quedado en la ciudad y su región.

${ }^{141}$ MV, p. 329.

${ }^{142}$ TA, p. 81 .

${ }^{143}$ Negre, Martí 2015.

${ }^{144}$ AMA, p. 42; VHI, p. 322.

${ }^{145}$ Artigues 2003.

${ }^{146}$ Agradecemos la lectura del sello a Tawfiq Ibrahim (Real Academia de la Historia), así como sus oportunas indicaciones en cuanto a paralelos.
} 
Desplazándonos hacia la retaguardia de la frontera, otra fortificación ha sido excavada recientemente con resultados que concuerdan con nuestra hipótesis. Se trata de la fortaleza de Cervera del Maestrat (Castelló), identificada por las fuentes prosopográficas como Ğirbīra en el siglo XII ${ }^{147}$ y que nosotros correlacionamos con el hiṣn Kūna idrisiano ${ }^{148}$. Localizado en la cima del teso de Cervera, este punto permite el control de las dos vías principales paralelas a la costa y de la transversal entre Peníscola y el interior ${ }^{149}$. Los trabajos realizados en el año 2000 en el interior del recinto fortificado pusieron en relieve un nivel fundacional que amortizaba los estratos ibéricos, creando un suelo de tierra prensada y compactada, vinculado al cuerpo inferior de la torre de levante que fue realizado con grandes bloques calcáreos irregulares ligados con mortero de cal, que definía una primera fase de uso asociada a cerámicas de la segunda mitad del siglo $\mathrm{X}^{150}$.

Poco más al sur encontramos otro ejemplo cuyas fases más antiguas pueden adscribirse al período califal. Se trata de la fortaleza de Alcalà de Xivert (Castelló), identificada en las fuentes árabes como ḥiṣn Šibart. El sector superior de la fortaleza, de unos $600 \mathrm{~m}^{2}$, presenta reformas claras de época almohade, pero se asienta sobre algunas construcciones anteriores. La excavación en el interior del patio de armas reveló los niveles fundacionales de la misma, cuyos materiales presentan un horizonte homogéneo que puede atribuirse al período califal y que son amortizados por una posterior reforma interna del recinto durante la primera mitad del siglo $\mathrm{XI}^{151}$.

Respecto a los límites de los aqālìm controlados por estos hușīn, hemos de acudir a las fuentes latinas posteriores a la conquista cristiana para realizar una propuesta de restitución, pues son estas mismas fuentes las que confirman, en muchos casos, la participación de andalusíes en la delimitación de los antiguos términos de estas fortalezas ${ }^{152}$. Si bien en un primer momento las fortificaciones serían menos numerosas, y por tanto, los distritos tendrían una extensión mayor, estos debieron ir segregándose a medida que el proceso añadía enclaves al sistema. En su configuración definitiva, la contrastación entre la ubicación de los ḥuṣunn idrisianos y las cartas de poblamiento, donaciones señoriales y otra documentación administrativa similar nos permiten inferir unos límites plausibles para los mismos.

\footnotetext{
${ }^{147}$ TKS, ed. de Alarcón y González, bio. 2167.

${ }^{148}$ Martí, Negre 2014; Negre en prensa.

${ }^{149}$ Negre 2013b.

${ }^{150}$ Vizcaíno et al. 2000, p. 361.

${ }^{151}$ Falomir, Negre, Aguilella, Arquer en prensa.

${ }^{152}$ Royo 2017.
} 


\subsection{El proceso de estatización de la frontera a través de sus contingentes militares}

Desde un punto de vista militar, la tendencia a la escasa o nula presencia del poder central observada durante la mayor parte del emirato en Tortosa cambiará de forma sensible a partir de la década de los veinte del siglo X, coincidiendo con el triunfo de 'Abd al-Raḥmān al-Nāṣir sobre los diferentes rebeldes andalusíes. Así, los ğunūd fronterizos participaron en la expedición omeya contra Pamplona (924) $)^{153}$, pero junto a ellos combatieron ăgnād (sing. ğund) enviados por Córdoba ${ }^{154}$, guardias palatinos del emir (hašam) y reclutas (maȟ̌̌udūn) procedentes del conjunto de al-Andalus ${ }^{155}$. Las fuerzas locales parece que siguieron jugando un rol destacable en sucesos armados posteriores. En el 941 los habitantes de Tortosa (ahl Turțūša) solicitaron del califa una exención de impuestos porque soportaban las agresiones de sus vecinos cristianos $^{156}$, y en el 975 la gente de las fronteras orientales (ahl al-thugu ür alšarqiyya) recibió acciones hostiles de los mismos enemigos ${ }^{157}$.

Sin embargo, las tropas vinculadas al califa omeya ya no dejarán de hacer acto de presencia, siendo buena muestra de ello la intervención de la flota cordobesa en las costas catalanas para responder a los avances del conde de Barcelona en la frontera tortosina ${ }^{158}$. Si la armada del 933 llevaba como tripulantes a unidades de la guardia palatina califal ( hašam), la del 935 desembarcó tropas regulares cordobesas ( ğund) en diferentes puntos del litoral barcelonés y gerundense ${ }^{159}$. Ciertamente, el estudio de los efecti-

${ }^{153} \mathrm{MV}$, p. 123.

${ }^{154}$ Ibidem, p. 122.

${ }^{155}$ MV, pp. 122, 125; BML, II, pp. 196, 199.

${ }^{156}$ MV, p. 316.

${ }^{157}$ MVII, p. 216.

${ }^{158}$ Martí 1992,pp. 28-29; 2017,p. 682; Gibert 2011,pp. 259, 420, 433, 441. Un vaciado del

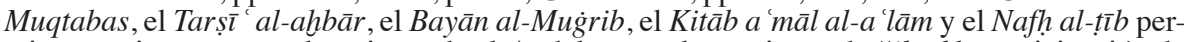
mite apreciar como en el conjunto de al-Andalus y en las acciones de ğihād la participación de las unidades vinculadas al poder central casi se multiplica por 2,4 a partir del 920 (Suñé 2017, pp. 124-126, 169-173). Mientras las tropas regulares y la guardia palatina omeya aparecen en 13 ocasiones entre el 808 y el 920 (MII/1, ed. Makkī,pp. 132, 420, 428, 458; BML, II, pp. 74, 115, 176, 180; TA, p. 30; MII/2, pp. 271-273, 296, 325), los mismos efectivos están representados en 31 de los enfrentamientos desde esa última fecha y hasta el 1010 (MV, pp. 108, 122-123, 125, 225, 230, 248, 257, 267, 270-271, 289, 293 , 295, 296-297, 300, 306, 310, 314, 316; BML, II, pp. 188, 196, 199, 282, 317; TA, p. 43; MVII, pp. 221-223; KA, pp. 63, 70, 72; NT I, p. 414; BML III, pp. 4-5, 23, 49, 51, 88, 89, 94-95).

${ }^{159}$ MV, pp. 217-218, 248. En el año 943 la flota omeya volvió a hacer acto de presencia en las costas catalanas, probablemente en respuesta a la pérdida momentánea de Tarragona, que debió producirse en torno al 942 (TA, p. 81; MD, ed. Mar' 1 , vol. I, p. 126; TI IV, pp. 184, 187; NT I, pp. 366, 384-385; Benet 1988, pp. 50-53). Una veintena de años más tarde, en el 964, el asedio del conde Borrell (948-992) sobre Tortosa estuvo a punto de provocar una nueva expedición 
vos andalusíes implicados en la defensa de Tortosa sugiere que, a partir de la década del 920, la imposición de al-Nāṣir sobre las autoridades locales y la consecuente multiplicación de sus ingresos fiscales posibilitaron también un incremento considerable de la actuación de las tropas califales en este territorio ${ }^{160}$.

Sobre la importancia de las fuerzas navales durante el califato y el interés del poder cordobés en el control de las costas de al-Andalus, cabe aún destacar un elemento importante como es la construcción y reparación de arsenales durante este período en algunas de las principales plazas portuarias de sus dominios. Este proceso está bien documentado en la ciudad de Tortosa, donde una estela fundacional nos recuerda la finalización de su construcción en el año 945 bajo la supervisión del $q \bar{a}$ 'id 'Abd al-Raḥmān b. Muḥammad b. al-Naz̧⿻̄ām ${ }^{161}$. Pero no es el único caso. En Dénia se constata la construcción de unas importantes atarazanas, cuya fundación debe retrotraerse al califato, destinadas principalmente a la construcción de navíos para la flota califal ${ }^{162}$. Más al sur encontramos la ciudad de Almería, cuya fundación en 955 fue acompañada de la integración en sus murallas de sus atarazanas, que como mínimo estarían en funcionamiento desde el año $933^{163}$.

Finalmente, otro caso significativo es el del arsenal de Algeciras, reconstruido por orden del califa al-Nāșirir ${ }^{164}$ sobre los restos de las atarazanas emirales, según noticia recogida por Ibn al-Qūtịyya ${ }^{165}$. En este caso, además, disponemos de importantes restos arqueológicos que nos permiten conocer mejor la morfología de este tipo de edificios, verificando una gran construcción con muros de más de tres metros de ancho levantados con grandes sillares dispuestos a tizón ${ }^{166}$. Su papel fundamental en el control del Mediterráneo occidental y sus relaciones comerciales, en liza durante este período entre omeyas y fatimíes, fue uno de los elementos claves que llevó al aumento de la presencia e influencia califales en todos los puertos marítimos, entre los cuales Tortosa jugó un papel fundamental.

marítima, pero el levantamiento del bloqueo no hizo necesaria la intervención de la armada cordobesa (IAG, vol. I, pp. 478-479).

${ }^{160}$ MII/1, ed. Makkī, p. 292; NT I, p. 348; TI IV, p. 170; BML, II, p. 247; KA, p. 38.

${ }^{161}$ Bramon 2000, doc. 415.

${ }^{162}$ Azuar 1992-1993, p. 42.

${ }_{163}^{163}$ AMA, p. 28; MV, p. 218.

${ }^{164} \mathrm{KR}, \mathrm{pp} .90-93$.

${ }^{165}$ KTI, p. 12; FA, p. 55; Lirola 1993, pp. 84-85, 319-320.

${ }^{166}$ Bravo et al. 2009, pp. 149-150. 


\section{CONCLUSIONES}

Llegados a este punto, la principal conclusión que se observa a partir de los argumentos presentados es la creciente influencia que ejerció el poder omeya en el control territorial de Tortosa, un proceso que alcanzaría su zenit durante el califato.

En cuanto a la organización administrativa de Tortosa, cabe destacar algunos indicios que apuntan hacia la continuidad de las divisiones territoriales visigodas durante los primeros momentos de dominio andalusí. Esta pervivencia se intuye, por ejemplo, a través de la posible equivalencia entre los a 'māl/ahwwāz andalusíes y las diocesis/territoria visigodas, así como en la supervivencia de parte de los límites de estas divisiones. No obstante, las fuentes árabes muestran también claros indicios del interés en la implementación de estructuras de gestión propias, como la kūra o el iqlīm, desde momentos muy tempranos, aunque de forma desigual entre la frontera o las zonas más cercanas a la capital. De esta manera, es ya en época de 'Abd al-Raḥmān al-Nāṣir cuando tenemos evidencias consistentes de una división administrativa andalusí plenamente estandarizada. Para la frontera, esta organización se basaría en la continuidad del 'amal, la circunscripción urbana, que a su vez estaría subdividida en unidades menores, los aqālìm, cuyo centro territorial se establecería en un hiṣn, del cual dependerían los asentamientos rurales establecidos dentro de sus límites.

Complementariamente, esta ordenación administrativa coexistiría con otra zonificación, de tipo militar y aparición tardía, que englobaría parte de uno o varios de estos $a^{\prime} m \bar{a} l$ dentro de un territorio fronterizo común ( $\left.\underline{\operatorname{ta}} \dot{g} r\right)$. El uso de este término como referencia territorial precisa no se documenta hasta mediados del siglo $\mathrm{X}$, momento a partir del cual pensamos que empezaría a generalizarse dentro de la burocracia y los escritos vinculados a la corte omeya. Bajo esta denominación se definía el área de linde, flexible y móvil, entre Dār al-Islām y Dār al-ḥarb, sin que esta tuviese que ser coincidente con las demarcaciones administrativas por las que se extendía. Así, mientras que el 'amal de Tortosa durante el califato englobaría los territorios comprendidos entre Mequinenza y Orpesa, su tag $r$ estaría volcado en el entorno del valle del Ebro. Al menos para el caso de Tortosa, no parece tratarse de regiones administrativas que suplanten a las circunscripciones urbanas, sino de marcos de actuación de las tropas vinculados a la defensa de los confines de al-Andalus.

Paralelamente, desde la década del 920 se constata una incorporación cada vez mayor de unidades vinculadas al califa omeya de Córdoba entre los contingentes locales movilizados y mantenidos por el gobernador provincial de Tortosa. Este proceso viene acompañado por la construcción progresiva de una red de fortalezas en los distintos aqālīm del 'amal de Tortosa. Todas aque- 
llas que han sido excavadas presentan un horizonte fundacional ligado a este mismo momento. Sus funciones fueron diversas, vinculadas tanto a los aspectos puramente militares como a la articulación de formas más eficientes en el control del territorio y su fiscalidad. El éxito omeya en este aspecto se manifiesta de manera evidente en el incremento espectacular de las tributaciones en época califal, cuando se multiplican por seis respecto a la centuria anterior.

A modo de corolario, es importante señalar la estrecha vinculación que Tortosa mantuvo con el poder cordobés a lo largo del período omeya, acentuada sobremanera durante el califato ${ }^{167}$. Es difícil dar una respuesta definitiva a los motivos exactos que llevaron a esta situación, aunque podemos aventurar dos hipótesis, no excluyentes, al respecto. Según la primera, su ubicación como doble frontera terrestre y marítima le habría conferido una importancia geoestratégica superior a otras zonas, lo que habría cristalizado en un mayor interés del Estado omeya por mantener su influencia sobre la misma. La segunda propone la incapacidad de los grupos locales de este territorio para constituir poderes equiparables a los observados en el resto del valle del Ebro y otros sectores fronterizos. En este sentido, no se conocen para nuestro espacio de estudio dinastías como las de los Banū Di 1-Nūn, los Banū Razīn, los Banū Qasī, los Banū 'Amrūs o los Banū Tư̆̄īb, y el intento de los bahriyyūn por establecer un poder autónomo en la segunda mitad del siglo IX solo conoció el éxito tras marcharse de Tortosa.

\section{BIBLIOGRAFIA CITADA}

FUENTES

AMA = Al-Rāzī (887-955), Ahbār mulūk al-Andalus:

Catalán, Diego; Andrés, M. Soledad de (ed.) (1975) Crónica del Moro Rasis. Versión del Ajbār mulūk al-Andalus de Aḥmad ibn Muhammad ibn Mūsà al-Rāzī, 889-955; romanzada para el rey don Dionís de Portugal hacia 1300 por Mahomad, alarife, y Gil Pérez, clérigo de don Perianes Porçel, Madrid, Gredos.

ANT = Liutprando de Cremona (m. 972), Antapodosis:

Pertz, Georg Heinrich (ed.) (1839), Monumenta Germaniae Historica inde ab anno Christi quingentesimo usque ad annum millesimum et quingentesimum, Hanover, Impensis Bibliopolii Aulici Hahniani, vol. V, pp. 264-339.

${ }^{167}$ Manzano 1991, p. 83. 
$\mathrm{ARF}=$ Annales regni Francorum (c. 829):

Kurze, Friedrich (ed.) (1895), Annales regni Francorum inde ab a. 741 usque ad a. 829, qui dicuntur Annales Laurissenses maiores et Einhardi, Hanover, Impensis Bibliopolii Hahniani (Scriptores rerum Germanicarum in usum scholarum ex Monumentis Germaniae Historicis separatim editi).

$\mathrm{BML}=\mathrm{Ibn}$ 'Id̄ārī (c. 1312-1313), Al-Bayān al-Mug̈rib:

Colin, Georges Séraphin; Lévi-Provençal, Evariste (ed.) (1948-1951), Kitāb al-Bayān al-Mugrrib fì ahbār al-Andalus wa-l-Mag̀rib li-Ibn 'Id̄ārī l-Marrākuš̄, 2 vols, Leiden, E. J. Brill.

BML III = Ibn 'Id̄ārī (c. 1312-1313), Al-Bayān al-Muġrib III:

Lévi-Provençal, Evariste (ed.) (1930), Al-Bayān al-Muğrib fì ahbār mulūk al-Andalus wa-l-Magirib li-Ibn al- 'Abbās Ibn 'Id̄ārī l-Marrākuš̄̃ . Al-ğuz' al-tālit , París, Libraire orientaliste Paul Geuthner.

$\mathrm{CAR}=$ Corpus Agrimensorum Romanorum (c. s. VI):

Thulin, Carl (ed.) (1913), Corpus Agrimensorum Romanorum. Opuscula Agrimensorum Veterum, Leipzig, Teubner.

CGpI = Cronica Gothorum pseudo-Isidoriana $(\mathrm{s} . \mathrm{XI})$ :

González Muñoz, Fernando (trad.) (2000), Cronica Gothorum pseudo-Isidoriana (ms. Paris BN 6113), Noia (A Coruña), Toxosoutos.

CSCV $=$ Cartulario de Sant Cugat del Vallès (c. 875-1000):

Rius, Jose (ed.) (1945-1947), Cartulario de "Sant Cugat" del Vallès, Barcelona, CSIC. vol. I.

DCT = Diplomatari de la Catedral de Tortosa (1062-1193):

Virgili, Antoni (ed.) (1997), Diplomatari de la Catedral de Tortosa (10621193), Barcelona, Fundació Noguera.

DHV = Diplomática Hispano-visigoda:

Canellas, Ángel (ed.) (1979), Diplomática Hispano-Visigoda, Zaragoza, Institución Fernando el Católico.

$\mathrm{EN}=$ Ermoldo el Negro (red. 826), Poema:

Faral, Edmond (ed.) (1932), Poème sur Louis le Pieux et épitres au roi Pèpin, París, Libraire ancienne Honoré Champion.

FM = Ibn 'Abd al-Hakam (m. 871), Futūḥ Mișr wa-l-Magrib:

Torray, Charles (ed.) (2002), The History of the Conquest of Egypt, North Africa and Spain Known as the Futūh Mișr of 'Abd al-Hakam, Piscataway, Gorgias Press.

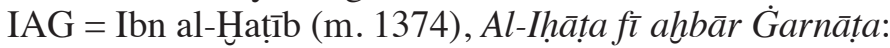

'Inān, Muḥammad 'Abd Allāh (ed.) (1973-1977), Al-iḥ̣̂ța fì ahbār Ġarnātạ, 4 vols, El Cairo, Maktabat al-Hुānǧī.

IS = Pseudo Ibn Qutayba (s. IX), Al-imāma wa-l-siyāsa, al-ma'ruf bi-tārīj al-julafā: 
Šīrī, 'Alī (ed.) (1990), Al-imāma wa-l-siyāsa, al-ma 'rufbi-tārīj al-julafā, Beirut, Dār al-Aḍ̂ā'

KA = Ibn al-Hुațīb (m. 1374), Kitāb a 'māl al-a lām:

Lévi-Provençal, Evariste (ed.) (1956), Ta'rīh Isbāniyyat al-Islāmiyya awkitāb a 'māl al-a 'ām fì man buw̄̄' qabla l-ihtilām min mulūk alIslām, Beirut, Dār al-Makšūf.

$\mathrm{KB}=\mathrm{Al}-\mathrm{Ya}^{\prime}$ qūbī (s. IX), Kitāb al-Buldān:

Wiet, Gaston (trad.) (1937), Textes et traductions d'auteurs orientaux. Tome premier: Ya 'kubi, Les Pays, El Cairo, Institut Français d'Archéologie Orientale.

KGZ = Al-Zuhrī (s. XII), Kitāb al-Ǧa rāafiyya:

Ḥāğğ Șādiq, Muḥammad (ed.) (1989), Kitāb al-Ǧa rāfiyya, Puerto Saíd - El Zahir, Maktabat al-Taqāfa al-Dīniyya.

KSA = Ibn Hawqal (s. X), Kitāb șūrat al-ard:

desc. (ed.) (1992), Kitāb șūrat al-ard li-Ibn Hawqal, Beirut, Dār maktabat al-ḥayāt; Kramers, Johannes Hendrik (ed.) (1938), Opus geographicorum auctore Ibn Haukal, Leiden, Brill.

KR = Al-Himyarī (m. 1327), Kitāb ar-Rawd:

'Abbās, Iḥsān (ed.) (1984), Al-Rawd al-mi țâr fì habar al-aqtar, Beirut, Maktabat Lubnān.

KTI = Ibn al-Qūṭiyya (m. 977), Kitāb tārīh iftitāḥ al-Andalus li-bn al-Qūtiyya al-Qurțubī:

Al-Ibyārī, Ibrāhīm (ed.) (1982) Tārīhh iftitāh al-Andalus, Beirut - El Cairo.

MII/1 = Ibn Ḥayyān (m. 1076), Al-Muqtabas II/1:

Makkī, Maḥmūd 'Alī (ed.) (2003), Al-safr al-țān̄̄ min Kitāb al-Muqtabas li-Ibn Hayyān al-Qurtubī, Riad, Markaz al-malik Fayșal li-l-buhūt wa-l-dirāsāt al-islāmiyya; Vallvé, Joaquín (ed.) (1999), Muqtabis II. Anales de los Emires de Córdoba Alhaquém I (180-206 H. / 796-822 J. C.) y Abderramán II (206-232 / 822-847). Edición facsímil de un manuscrito árabe de la Real Academia de la Historia, Madrid, Real Academia de la Historia.

MII/2 = Ibn Ḥayyān (m. 1076), Al-Muqtabas II/2:

Makkī, Maḥmūd 'Al̄̄ (ed.) (1973), Al-Muqtabas min anbā' ahl al-Andalus liIbn Hayyān al-Qurțub̄̄, Beirut, Dār al-Kitāb al- 'Arab̄i .

MIII = Ibn Ḥayyān (m. 1076), Al-Muqtabas III:

Martínez Antuña, Melchor (ed.) (1937), Al-qism al-țālit min Kitāb al-Muqtabas fì ta'rīh riğăl al-Andalus, París, Libraire orientaliste Paul Geuthner; Makkī, Mạ̣mūd 'Alī (ed.) (2009), Al-safr al-țulāt min kitāb al-muqtabas min abnā' ahl al-Andalus li-Ibn Hayyān al-Qurțūbì, Riyad, Markaz al-Malik Fayṣal li-1-Buḥụt wa-1-Dirāsāt al-Islāmiyya. 
MV = Ibn Hayyān (m. 1076), Al-Muqtabas V:

Chalmeta, Pedro; Corriente, Federico; Șubḥ, Mạ̣mūd (ed.) (1979), Al-Muqtabas li-Ibn Hayyān al-Qurțbī (al-ğuz' al-hāmis), Madrid - Rabat, Instituto Hispano-Árabe de Cultura - Kulliyat al-Ādāb.

MVII = Ibn Ḥayyān (m. 1076), Al-Muqtabas VII:

Al-Ḥağǧ̄i ' 'Abd al-Raḥmān 'Alī (ed.) (1965), Al-Muqtabas fì ahbār balad alAndalus, Beirut, Dār al-Taqāfa.

MD = Al-Mas 'ūdī (m. 957), Murūğ al-dahab:

Barbier, C.; Pavet, A. (ed. y trad.) (1861-1877), Les prairies d'or, París, Imprimerie Impériale; Mar'̄in, Kamāl Ḥasan (ed.) (2005), Murūğ al-ḍahab wa-ma 'ädin al-ğawhar, 4 vols.,Beirut, al-Maktaba al-'Așriyya.

NT = Al-Maqqarī (1577-1632), Nafh al-țı̄b:

'Abbās, Iḥsān (ed.) (1988), Naf̣̣ al-ṭīb min ġuṣn al-Andalus al-rațīb, 8 vols., Beirut, Dār Șādir.

RACGG = Ravennatis Anonymi Cosmographia et Guidonis Geografica (s. VII-IX):

Pinder, Moritz; Parthey, Gustav (ed.) (1860), Ravennatis anonymi cosmographia et Guidonis geographica, Berlín, Friderici Nicolai.

TA = Al- 'Udrī (1003-1085), Tarșī' al-ahbār:

Al-Ahwānī, 'Abd al- 'Azīz (ed.) (1965), Nușūṣ 'an al-Andalus min kitāb tarṣì ' al-ahbār wa-tanwī' al-ātār wa-l-bustān fì garā'ib al-buldān wa-lmasālik ilà ğamī 'al-mamālik, Madrid, Instituto de Estudios Islámicos.

TI = Ibn Haldūn (c. 1375-1378), Kitāb al- ibar:

H. Šihāada, S. Zakkār (ed.) (2000-2001), Ta'rīh Ibn Haldūn al-musamma Dīwān al-mubtada' wa-l-habar fì ta'rīh al- 'arab wa-l-barbar waman 'āṣara-hum man dawī l-ša'n al-akbar, 8 vols., Beirut, Dār alFikr.

TKS = Ibn al-Abbār (1199-1260) Takmila li kitāb aṣ-șila:

Alarcón, Maximiliano y González, Cándido Ángel (ed.) (1915) Apéndice a la edición Codera de la "Tecmila" de Aben al-Abbar, "Miscelánea de Estudios y Textos Árabes", pp. 147-690 Madrid, Centro de Estudios Históricos; al- 'Aț̣ār al-Husayn̄̄, 'Izzat (ed.) (1955) Al-takmila li kitāb al-șila, El Cairo, Maktab Našr al-Taqāfa al-Islāmiya, 2 vols.

$\mathrm{UM}=\mathrm{Al}$-Idrīsī (1100-1165), Uns al-muhă wa-rawd al-fură̆:

Mizal, Jassim Abid (ed.) (1989) Los caminos de al-Andalus en el siglo XII, Madrid, CSIC.

VHI = Astrónomo (c. 840-841), Vita Hludowici imperatoris:

Tremp, Ernst (ed.) (1995), Die Taten Kaiser Ludwigs / Thegan. Das Leben Kaiser Ludwigs / Astronomus, Hanover, Hahnsche Buchhandlung (Monumenta Germaniae Historica: Scriptores: 7, Scriptores rerum Germanicarum in usum scholarum separatim editi; 64). 


\section{ESTUDIOS}

Acién, Manuel (2000), La herencia del protofeudalismo visigodo frente a la imposición del estado islámico, "Anejos de AEspA” 23, pp. 429-441.

Acién, Manuel; Manzano, Eduardo (2009), Organización social y administración política en Al-Ándalus bajo el emirato, "Territorio, Sociedad y Poder" Anejo 2, pp. 331-348.

Adserias, Maria; Pociña, César A.; Remolà, Josep Anton (2000), L'hàbitat suburbà portuari al sector afectat pel PERI 2 (Jaume I - Tabacalera). en Tarraco 99. Arqueologia d'una capital provincial romana, Tarragona, Universitat Rovira i Virgili, pp. 137-154.

Aguadé, Jorge (1976), Algunos hadices sobre la ocupación de Alejandría por un grupo de hispano-musulmanes, "Boletín de la Asociación Española de Orientalistas" 12/2, pp. 159-180.

Aguilar, Victoria (1997), Instituciones militares: el ejército, en Viguera, María Jesús (coord.), El retroceso territorial de al-Andalus: almorávides y almohades siglos XI al XIII, Madrid, Espasa Calpe, pp. 187-208. (Historia de España Menéndez Pidal; VIII-2).

Andreu, Ricard (2012), Edició crítica, traducció i estudi de l'Ars Gromatica siue Geometria Gisemvndi, Barcelona, Universitat Autònoma de Barcelona (tesis doctoral).

Artigues, Pere (2003), El hisn andalusí de Miravet. Segles X-XII (Miravet, Ribera d'Ebre), en Actes del II Congrés d'Arqueologia Medieval i Moderna a Catalunya, Sant Cugat del Vallès, ACRAM, pp. 755-764.

Azuar, Rafael (1992-1993), La Taifa de Denia en el comercio mediterráneo del siglo XI, "Anales de la Universidad de Alicante. Historia Medieval" 9, pp. 39-52.

Ballestín, Xavier (1994), Prosopografia dels fuqahā' $i$ 'ulamā' de la zona oriental del Tag̀r al-A là: Balagàa, Lārida, Turțūša, en Marín, Manuela (ed.), Estudios onomástico-biográficos de al-Andalus (homenaje a José M. ${ }^{a}$ Fórneas), Madrid, CSIC, pp. 55-119.

Ballestín, Xavier (1999), Els baḥiyyūn min ahl al-Andalus: un grup tribal a la mar, en Barceló, Miquel (coord.), Musulmans i Catalunya, Barcelona, Empúries, pp. 66-68.

Ballestín, Xavier (en prensa), La segmentación de grupos clánicos bereberes y la actividad de los bahriyyūn (gentes del mar) en el Mediterráneo Occidental durante la Alta Edad Media (Al-Andalus, Al-Magreb, Siqiliyya), en De la sociedad islámica a la feudal. Veinte años de al-Andalus, homenaje a Pierre Guichard, Granada - València, 9-14 de mayo de 1996. 
Barceló Perelló, Miquel (1978), Sobre la divisió administrativa de Mayurqa, "Butlletí de la Societat Arqueològica Lul-liana" 36, pp. 238-245.

Barceló Torres, Carmen (2009), Los falsos Sagunt de las fuentes árabes, "AlQanțara" 30/1, pp. 237-243.

Benet, Albert (1988), El procés d'independència de Catalunya (897-989), Sallent, Institut d'Arqueologia - Història i Ciències Naturals.

Bramon, Dolors (2000), De quan érem o no musulmans. Textos del 713 al 1010, Barcelona, Eumo.

Bravo, Salvador; Vila, Miguel; Trinidad, David; Dorado, Rafael (2009), Resultados de la actividad arqueológica preventiva en Avenida de la Marina, esquina calles Segismundo Moret y Teniente Riera de Algeciras (Cádiz), "Caetaria" 6-7, pp. 131-156.

Chalmeta, Pedro (1976), Simancas y Alhandega, "Hispania. Revista española de historia" 36/133, pp. 359-446.

Chalmeta, Pedro (1988), Las campañas califales en al-Andalus, en Bazzana, André (ed.), Guerre, fortification et habitat dans le monde méditerranéen au Moyen Âge, Madrid, Casa de Velázquez - Roma, École Française de Rome, pp. 33-42 (Castrum; 3).

Chalmeta, Pedro (1991), El concepto de țagr, en Sénac, Philippe (ed.), La Marche supérieure d'al-Andalus et l'Occident chrétien, Madrid, Casa de Velázquez - Zaragoza, Universidad de Zaragoza, pp. 15-28.

Cressier, Patrice (1984), Le chateau et la division territoriale dans l'Alpujarra médiévale: du hisn à la Ta a, "Mélanges de la Casa de Velázquez" 20, pp. 115-144.

Falomir, Ferran; Negre, Joan; Aguilella, Gustau; Arquer, Neus (en prensa), Noves perspectives en l'estudi del període andalusí als districtes meridionals de Tortosa. Resultats preliminars als jaciments castellonencs del Tossal de la Vila (Serra d'en Galceran), Xivert i Santa Llúcia (Alcalà de Xivert), en Sabaté, Flocel; Negre, Joan; Brufal, Jesús (eds.), Fortaleses medievals (segles VII-XI), Lleida, Pagès.

Flors, Enric (2010), Torre la Sal (Ribera de Cabanes, Castelló), Evolución del paisaje antrópico desde la prehistoria hasta el medioevo, Castelló de la Plana, Diputació de Castelló.

Folch, Cristian; Gibert, Jordi; Gonzalo, Xavier; Martí, Ramon; Martínez, Núria (2018), La fortificació antiga i medieval de Castellví de la Marca (Barcelona), primeres dades arqueològiques, "Treballs d'arqueologia" 22, pp. 83-105.

Gibert, Jordi (2011), L'Alta Edat Mitjana a la Catalunya Central (segles VIXI). Estudi històric i arqueològic de la conca mitjana del riu Llobregat, Bellaterra, Universitat Autònoma de Barcelona (tesis doctoral). 
Gonzalo, Xavier (2013), La integración de Tarrakūna y su territorio en al-Andalus (s. VIII), "Arqueología y Territorio Medieval” 20, pp. 11-30.

Gonzalo, Xavier (2015), El poblament altmedieval del territori de Tarragona: campanyes de prospecció arqueològica a l'Alt Camp i la Conca de Barberà (2012-2013). Primers resultats, en Actes del V Congrés d'Arqueologia medieval i moderna a Catalunya, Barcelona, Ajuntament de Barcelona, pp. 721-728.

Granja, Fernando de la (1966) La Marca Superior en la obra de al- 'Udrī, Zaragoza, Escuela de Estudios Medievales - Consejo Superior de Investigaciones Científicas.

Guichard, Pierre (1979), Animation maritime et développement urbain des côtes de l'Europe orientale et du Languedoc au Xe siècle, en Occident et Orient au $X^{e}$ siècle. Actes du IXe Congrès de la Société des historiens médiévistes de l'Enseignement Supérieur Public, Dijon, 2-4 juin, 1978, París, Les Belles Lettres, pp. 187-201.

Guichard, Pierre (1983), Les débuts de la piraterie andalouse en Méditerranée occidentale (798-813), "Revue de l'Occident Musulman et de la Méditerranée" 35/1, pp. 55-76.

Guichard, Pierre (2007), Le Castellar de la Morera d'Elche est il la Madîna d'al-Askar des textes arabes?, "MARQ, Arqueología y Museos" 2, pp. 99-105.

Lirola, Jorge (1993), El poder naval de Al-Andalus en la época del califato Omeya, Granada, Universidad de Granada.

Lorenzo, Jesús (en prensa), El tagr al-Andalus según los geógrafos y los compiladores musulmanes (ss. IX-XI), en Sabaté, Flocel; Negre, Joan; Brufal, Jesús (eds.), Fortaleses medievals (segles VII-XI), Lleida, Pagès.

Manzano, Eduardo (1991), La frontera de al-Andalus en la época de los Omeyas, Madrid, Consejo Superior de Investigaciones Científicas.

Manzano, Eduardo (1993), El asentamiento y la organización de los ŷund-s sirios en al-Andalus, "Al-Qanțara" 14/2, pp. 327-359.

Manzano, Eduardo (2006) Conquistadores, emires y califas: los omeyas y la formación de al-Andalus, Barcelona, Crítica.

Marín, Manuela (2004), La práctica del ribāt en al-Andalus (ss. III-V/IX-XI), en Azuar Ruiz, Rafael (coord.), El ribāt califal. Excavaciones y estudios (1984-1992), Madrid, Casa de Velázquez, pp. 191-201.

Martí, Ramon (1992), La primera expansió comtal a ponent del Llobregat. Una xarxa de castells originals. Qui són els pobladors?, en Pladevall, Antoni (dir.), Catalunya Romànica, Barcelona, Enciclopèdia Catalana, vol. 19, pp. 28-35. 
Martí, Ramon (1995), Territoria en transició al Pirineu medieval, en Actes del $3^{\text {er }}$ Curs d'Arqueologia d'Andorra, Andorra la Vella, Ministeri d'Afers Socials i Cultura, pp. 37-83.

Martí, Ramon (2017), Els Castellvell durant el segle X, artífexs $i$ veguers de la Marca de Barcelona, "Anuario de Estudios Medievales" 47/2, pp. 679-705.

Martí, Ramon; Negre, Joan (2014), Fortificaciones y edilicia de prestigio en el extremo oriental de la Marca Superior: Tortosa y su entorno, en Sabaté, Flocel; Brufal, Jesús (ed.), Arqueologia medieval: la ciutat, Lleida, Pagès.

Meouak, Mohamed (1993), Hiérarchie des fonctions militaires et corps d'armée en al-Andalus umayyade (II $/ V I I^{e}-I V^{e} / X^{e}$ siècles): nomenclature et essai d'interprétation, "Al-Qanțara" 14/2, pp. 361-392.

Meouak, Mohamed (1995), Toponymie, peuplement et division du territoire dans la province d'Almería à l'époque médiévale: l'apport des textes arabes, "Mélanges de la Casa de Velázquez" 31/1, pp. 173-222.

Meouak, Mohamed (2000), Administration des provinces et gouverneurs (wulā `'ummāl) dans l'Espagne umayyade, "Miscelánea de Estudios Árabes y Hebraicos" 49, pp. 105-116.

Miquel, André (2001), La géographie humaine du monde musulman jusqu'au milieu du 11 e siècle. Tome 1: Géographie et géographie humaine dans la littérature arabe des origines à 1050, París, École des Hautes Études en Sciences Sociales.

Molénat, Jean-Pierre (2005), L'organisation militaire des almohades, en Cressier, Patrice; Fierro, Maribel; Molina, Luis (eds.), Los almohades: problemas y perspectivas, Madrid, CSIC, vol. II, pp. 547-565.

Molina, Luis; Ávila, María Luisa (1985), La división territorial en la Marca Superior de al-Andalus, "Historia de Aragón" 3, pp. 11-30.

Molist, Núria; Bosch, Josep M. (2012), El cementiri medieval de Sant Miquel d'Olèrdola (Olèrdola, Alt Penedès), en Arqueologia funerària al nord-est peninsular (segles VI-XII), Barcelona, Museu d'Arqueologia de Catalunya, pp. 469-494.

Mu'nis, Husayn (1957) La división politico-administrativa de la España musulmana, "Revista del Instituto Egipcio de Estudios Islámicos" 5, pp. 79-135.

Negre, Joan (2013a), De Dertosa a Turțūša. L'extrem oriental d'al-Tagr alA 'là en el context del procés d'islamització d'al-Andalus, 2 vols., Barcelona, Universitat Autònoma de Barcelona (tesis doctoral).

Negre, Joan (2013b), Evolució de la xarxa viària del territori de Tortosa entre l'Antiguitat i l'Edat Mitjana, "Quaderns de Prehistòria i Arqueologia de Castelló" 31, pp. 209-228. 
Negre, Joan (2015), Espacios religiosos en el medio rural: rábidas, mezquitas y necrópolis en el ḥawz de Turțūša, en Sabaté, Flocel; Brufal, Jesús (eds.), Els espais sagrats, Lleida, Pagès.

Negre, Joan (en prensa), Sobre els orígens del castell d'Ulldecona: hịịn, castrum o alguna cosa diferent?, "Recerca" 18.

Negre, Joan; Lozano, Luís; Selma, Sergi (2018), Una primera aproximació als contextos ceràmics de cronologia andalusina de la fortalesa d'Orpesa, "Quaderns de Prehistòria i Arqueologia de Castelló" 36, pp. 231-256.

Negre, Joan; Martí, Ramon (2015), Urbanismo en la Marca Oriental de al-Andalus durante el Califato (940-974): el ejemplo de Madina Turtūša a través de las fuentes arqueológicas y escritas, "Sagvntvm" 47, pp. 187-201.

Picard, Christophe (2007), Bahriyyūn, émirs et califes: l'origine des equipages des flottes musulmanes en Méditerranée occidentale (VIII ${ }^{e}-X^{e}$ siècle), "Medieval Encounters" 13, pp. 413-451.

Rodríguez, Francesc; Macias, Josep M. (2016), Nuevo contexto cerámico de la segunda mitad del s. VII en Tarraco (Tarraconensis, RegnumVisigothorum), en Járrega, Ramon; Berni, Piero (eds.), Amphorae ex Hispania: paisajes de producción y consumo, Tarragona, ICAC-SECAH, pp. 936-952.

Rodríguez, Francesc; Macias, Josep M. (2018), Buscando el siglo VIII en el puerto de Tarracona: entre la residualidad y el desconocimiento, en Martín Viso, Iñaki; Fuentes, Patricia; Sastre, José Carlos; Catalán, Raúl (eds.), Cerámicas altomedievales en Hispania y su entorno (s. V-VIII d.C.), Valladolid, Glyphos, pp. 573-589.

Royo, Vicent (2017), Els origens del Maestrat històric. Identitat, convivència $i$ conflictes en una societat rural de frontera ( $s . X I I I-X V)$, Benicarló, Onada Edicions.

Selma, Sergi (2014), Les torres nord i sud-oest del Castell d'Orpesa (La Plana Alta), intervencions i recuperació, "Quaderns de Prehistòria i Arqueologia de Castelló" 32, pp. 223-234.

Selma, Sergi; Negre, Joan; Lozano, Luís (en prensa), La fortalesa andalusina d'Orpesa (segles X-XIII). Elements defensius, metrologia i registre material, en Sabaté, Flocel; Negre, Joan; Brufal, Jesús (eds.), Fortaleses medievals (segles VII-XI), Lleida, Pagès.

Sénac, Philippe (2000), La frontière et les hommes (VIII ${ }^{e}$ XII ${ }^{e}$ siècle). Le peuplement musulman au nord de l'Èbre et les débuts de la reconquête aragonaise, París, Maisonneuse \& Larose.

Souto, Juan Antonio (1992), El poblamiento del término de Zaragoza (siglos VIII-X): los datos de las fuentes geográficas e históricas, "Anaquel de Estudios Árabes" 3, pp. 113-152. 
Souviron, Sebastián (2009), Fiscalidad y control eclesiástico en la Hispania visigoda: supervisión de almas e impuestos, "Baetica. Estudio de Arte, Geografía e Historia” 31, pp. 275-289.

Suñé, Josep (2017), Ğihād, fiscalidad y sociedad en la Península Ibérica (7111172): evolución de la capacidad militar andalusí frente a los reinos y condados cristianos, Barcelona, Universitat de Barcelona (tesis doctoral).

Vallvé, Joaquin (1986), La división territorial de la España musulmana, Madrid, CSIC,

Valor, Magdalena; Ramírez, José (2001), La división geográfico-administrativa de al-Andalus, en Viguera, María Jesús; Castillo, Concepción (eds.), El esplendor de los Omeyas cordobeses. La civilización musulmana de Europa Occidental, Granada, Junta de Andalucía, pp. 264-273.

Viguera, María Jesús (1997), Historiografía, en Viguera, María Jesús (coord.), El retroceso territorial de al-Andalus: almorávides y almohades siglos XI al XIII, Madrid, Espasa Calpe pp. 1-37 (Historia de España Menéndez Pidal; VIII-2).

Viguera, María Jesús (2001), La organización militar en al-Andalus, "Revista de Historia Militar" 45/1, pp. 17-60.

Vizcaíno, David; Bravo, Eva María; De Antonio, José Manuel; Barrachina, Amparo (2000), Memoria de la intervención arqueológica en el castillo de Cervera del Maestre (Castellón), "Quaderns de Prehistòria i Arqueologia de Castelló” 21, pp. 357-396.

Fecha de recepción del artículo: enero 2018

Fecha de aceptación y versión final: noviembre 2018 